\title{
The C-terminal helix in the YjeQ zinc-finger domain catalyzes the release of RbfA during $30 S$ ribosome subunit assembly
}

\author{
AJITHA JEGANATHAN, AIDA RAZI, BRETT THURLOW, and JOAQUIN ORTEGA \\ Department of Biochemistry and Biomedical Sciences, M.G. DeGroote Institute for Infectious Diseases Research, McMaster University, \\ Hamilton, Ontario, Canada L8S 4K1
}

\begin{abstract}
YjeQ (also called RsgA) and RbfA proteins in Escherichia coli bind to immature 30S ribosome subunits at late stages of assembly to assist folding of the decoding center. A key step for the subunit to enter the pool of actively translating ribosomes is the release of these factors. YjeQ promotes dissociation of RbfA during the final stages of maturation; however, the mechanism implementing this functional interplay has not been elucidated. YjeQ features an amino-terminal oligonucleotide/oligosaccharide binding domain, a central GTPase module and a carboxy-terminal zinc-finger domain. We found that the zinc-finger domain is comprised of two functional motifs: the region coordinating the zinc ion and a carboxy-terminal $\alpha$-helix. The first motif is essential for the anchoring of YjeQ to the $30 \mathrm{~S}$ subunit and the carboxy-terminal $\alpha$-helix facilitates the removal of RbfA once the $30 \mathrm{~S}$ subunit reaches the mature state. Furthermore, the ability of the mature $30 \mathrm{~S}$ subunit to stimulate YjeQ GTPase activity also depends on the carboxy-terminal $\alpha$-helix. Our data are consistent with a model in which YjeQ uses this carboxy-terminal $\alpha$-helix as a sensor to gauge the conformation of helix 44, an essential motif of the decoding center. According to this model, the mature conformation of helix 44 is sensed by the carboxy-terminal $\alpha$-helix, which in turn stimulates the YjeQ GTPase activity. Hydrolysis of GTP is believed to assist the release of YjeQ from the mature $30 \mathrm{~S}$ subunit through a still uncharacterized mechanism. These results identify the structural determinants in YjeQ that implement the functional interplay with RbfA.
\end{abstract}

Keywords: ribosome assembly; 30S subunit; YjeQ protein; RsgA protein; RbfA protein; GTPase

\section{INTRODUCTION}

The $70 \mathrm{~S}$ ribosome is the macromolecular complex performing protein synthesis. It is comprised of two functional subunits, the large $50 \mathrm{~S}$ and the small $30 \mathrm{~S}$ subunits (Ramakrishnan 2002). The $50 \mathrm{~S}$ subunit is composed of the $23 \mathrm{~S}$ and 5S rRNAs as well as 34 ribosomal proteins (r-proteins) (Ban et al. 2000; Harms et al. 2001). The 50S subunit houses the peptidyl transferase center (PTC), which is the catalytic site for peptide bond formation. The $30 \mathrm{~S}$ subunit contains only one molecule of rRNA (16S rRNA) and 21 r-proteins (Wimberly et al. 2000). The functional core in the 30S subunit is the decoding center, which translates the sequence of the mRNA into protein. Considering the size and complexity of the ribosome, it is a remarkable feat that assembly of the ribosomal subunits in bacterial cells occurs with such high precision and efficiency.

A constant challenge for the cell to maintain high efficiency in the process of ribosome assembly is to ensure that the rRNA molecules stay in a productive line of folding toward the mature structure, without falling into kinetic traps

Corresponding author: ortegaj@mcmaster.ca

Article published online ahead of print. Article and publication date are at http://www.rnajournal.org/cgi/doi/10.1261/rna.049171.114. Freely available online through the RNA Open Access option.
(Woodson 2008, 2011; Shajani et al. 2011). In particular, the folding events involving the maturation of the decoding center in the 30S subunit and PTC in the 50S subunit, occurring at the late stages of assembly (Jomaa et al. 2011a, 2014; Guo et al. 2013; Leong et al. 2013; Li et al. 2013) have a strong tendency to fall into local energy minima. Therefore, bacterial cells have acquired a number of protein factors that are dedicated to assist the folding of these motifs critical for ribosome function (Wilson and Nierhaus 2007); however, it is still not understood how they perform their function.

There are at least four protein factors (YjeQ [or RsgA], RbfA, RimM, and Era) that assist the folding of the decoding center during the late stages of assembly of the 30 S subunit. Their roles in the maturation of the functional core of the $30 \mathrm{~S}$ subunit may entail facilitating proper $17 \mathrm{~S}$ rRNA folding, assisting processing of the rRNA, or mediating protein-RNA interactions. Cryo-electron microscopy (cryo-EM) (Sharma et al. 2005; Datta et al. 2007; Guo et al. 2011; Jomaa et al. 2011b) revealed that at least three factors, Era, YjeQ, and RbfA bind at or in close proximity to the decoding center at sites that are not overlapping, indicating that simultaneous

C 2015 Jeganathan et al. This article, published in $R N A$, is available under a Creative Commons License (Attribution 4.0 International), as described at http://creativecommons.org/licenses/by/4.0/. 
binding is stereochemically possible. Consistently, genetic experiments (Bylund et al. 1998, 2001; Inoue et al. 2003, 2006; Campbell and Brown 2008) suggested that these factors operate in conjunction rather than independently. Indeed, a recent study (Goto et al. 2011) described that binding of YjeQ stimulates the removal of RbfA bound to the mature 30S subunit. The RbfA protein binds to the small ribosomal subunit at the junction between the body and head, most likely when the particle is still in an immature state and alters the position of helix 44 and 45 (Datta et al. 2007). This study (Goto et al. 2011) suggested that one of the functions of $Y j e Q$ is assisting the release of RbfA and perhaps other assembly factors, once maturation of the ribosomal particle is completed. Therefore, accumulated evidence suggests that YjeQ, RbfA, RimM, and Era function together to ensure the maturation of the functional core of the $30 \mathrm{~S}$ subunit.

Although the question here at large is how these four factors cooperate to ensure proper maturation of the decoding center, the specific focus in this study is to identify the motifs in YjeQ that implement the functional interplay between YjeQ and RbfA (Goto et al. 2011).

The YjeQ protein is a GTPase broadly conserved across most bacterial species. It exhibits slow intrinsic GTPase activity; however, interaction with the $30 \mathrm{~S}$ subunit enhances this activity by 160-fold (Daigle and Brown 2004). YjeQ is structurally well conserved (Levdikov et al. 2004; Shin et al. 2004; Nichols et al. 2007) featuring an amino-terminal oligonucleotide/oligosaccharide binding (OB-fold) domain, a central GTPase module and a carboxy-terminal zinc-finger domain (Supplemental Fig. S1A). The OB-fold domain consists of antiparallel $\beta$-sheets that come together forming a $\beta$-barrel. In the YjeQ GTPase domain the characteristic G motifs mediating the nucleotide binding (G1 (Walker A, P-loop)-G2 (T)-G3 (Walker B)-G4 (N/TKxD)-G5 [(T/G)(C/S)A]) are circularly permutated and adopt a G4-G5-G1-G2-G3 pattern. Work in the prototype ras GTPase showed that nucleotide binding and hydrolysis leads to conformational changes typically confined to two loops in the GTPase domain known as switch I and switch II (Hall et al. 2002). Switch I in YjeQ encompass the G2-loop and it is disordered in the YjeQ structures. The G3 loop constitutes the switch II, which in this case is a long stretch of amino acids connecting the GTPase domain with the carboxy-terminal zinc-finger domain. Therefore, switch I and II are well positioned in YjeQ to propagate the conformational changes occurring as a result of the GTP hydrolysis to the upstream OB-fold and downstream zinc-finger domain, respectively. The carboxy-terminal zinc-finger domain in YjeQ is comprised of a $3^{10}$-helix and a long loop containing three cysteine residues and a histidine that mediate the tetrahedral coordination of one zinc ion. Beyond this loop there are two additional $\alpha$-helices. The function of the last carboxy-terminal $\alpha$-helix is unclear, as it is not directly required to coordinate the zinc ion (Supplemental Fig. S1A).

It has been described that the OB-fold domain is essential for binding to the $30 \mathrm{~S}$ subunit and GTPase stimulation
(Daigle and Brown 2004), but a specific role for the GTPase and zinc-finger domains has not been assigned. Here, we found that the zinc-finger domain is comprised of two functional motifs. The region coordinating the zinc ion, which is essential for efficient binding of YjeQ to the 30S subunit and the carboxy-terminal $\alpha$-helix that is necessary for the removal of RbfA from the mature 30 S subunit. In addition, it has been described (Goto et al. 2011) that when the 30S subunit reaches the mature state, the GTPase activity of the bound YjeQ increases. We found that the ability of the mature $30 \mathrm{~S}$ subunit to stimulate YjeQ GTPase activity also depends on the presence of the carboxy-terminal $\alpha$-helix in the zinc-finger domain. Our data are consistent with a model in which YjeQ uses the carboxy-terminal $\alpha$-helix as a sensor to gauge the conformation of helix 44, an essential motif of the decoding center that only adopts its mature conformation at the very end of the assembly process. According to this model, the carboxy-terminal $\alpha$-helix senses that helix 44 has reached the mature conformation and triggers GTP hydrolysis facilitating the release of YjeQ from the mature $30 \mathrm{~S}$ subunit through a still uncharacterized mechanism. Release of the assembly factors is necessary for the mature $30 \mathrm{~S}$ subunit to associate with the $50 \mathrm{~S}$ subunit and engage in translation.

\section{RESULTS}

\section{The carboxy-terminal zinc-finger domain of YjeQ provides structural stability to the protein}

To determine the specific function of the zinc-finger domain of YjeQ in assisting the assembly of the 30 S subunit, we constructed three protein variants with different truncations in the carboxy-terminal region (Supplemental Fig. S1B). In the first variant (YjeQ M1), the entire zinc-finger domain was removed by introducing a stop codon in the position of Leu 278 (Escherichia coli numbering) located in the loop connecting this domain with the GTPase domain. For the second variant the stop codon was introduced in the position of Phe 287, right after the $3^{10}$-helix, therefore removing the loop coordinating the zinc ion. Finally, for the third variant (YjeQ M3) the stop codon was introduced in the position of Lys 320 removing the carboxy-terminal $\alpha$-helix, but not the loop coordinating the zinc ion.

To compare the stability of these YjeQ variants with the wild-type YjeQ protein, we performed a precipitation test in which the proteins were incubated at different temperatures and $\mathrm{NH}_{4} \mathrm{Cl}$ concentrations (Supplemental Fig. S1C). From these experiments we concluded that in order to maintain the YjeQ variants in solution under the low salt conditions required for our binding assays with the $30 \mathrm{~S}$ ribosome subunits (see below), the temperature had to be maintained at $16^{\circ} \mathrm{C}$ or lower.

In addition, to ensure that these carboxy-terminal deletions did not produce a global unfolding of the protein, the wild-type YjeQ protein and YjeQ variants were analyzed by 
circular dichroism (CD) (Supplemental Fig. S2). This technique, consistent with the results from the precipitation test, showed that at a temperature of $25^{\circ} \mathrm{C}$ or lower the $\mathrm{YjeQ}$ variants were stable and properly folded. However, the carboxy-terminal zinc-finger domain of the protein was necessary for the YjeQ protein to remain structurally stable at higher temperatures.

Finally, we tested the effect of removing the zinc ion on the stability of YjeQ. Three cysteine residues (Cys 297, Cys 302, and Cys 310) and a histidine (His 305) mediate the tetrahedral coordination of one zinc ion to the carboxy-terminal domain of YjeQ (Supplemental Fig. S1A). To remove the ability of the domain to coordinate the zinc ion, Cys 297 and Cys 310 residues were mutated to alanine (YjeQ M5). We found that when expressing this variant most of the protein produced was insoluble regardless of the temperature used in the incubation of the culture $\left(16^{\circ} \mathrm{C}, 25^{\circ} \mathrm{C}\right.$, and $37^{\circ} \mathrm{C}$ ) (data not shown). This result suggested that in the full-length $\mathrm{YjeQ}$, the presence of the zinc ion is important not only for the folding of the zinc-finger domain, but also for the proper folding of the amino-terminal OB fold and GTPase domains.

\section{YjeQ requires the carboxy-terminal zinc-finger domain to bind the mature $30 \mathrm{~S}$ subunit}

The OB-fold domain of YjeQ has already been identified as a necessary motif for the binding of the protein to the $30 \mathrm{~S}$ subunits and stimulation of its GTPase activity (Daigle and Brown 2004). Here, to determine the role of the zinc-finger domain of $\mathrm{YjeQ}$ in the binding of the protein to the small ribosome subunit, we tested the ability of the carboxy-terminal truncation variants of YjeQ (Supplemental Fig. S1B) to bind mature $30 \mathrm{~S}$ and immature $30 \mathrm{~S}$ subunits purified from yjeQ null E. coli cells. To this end, we used filtration assays in which a mixture of the $30 \mathrm{~S}$ subunits (mature or immature) with YjeQ (full-length or variants) was incubated at $16^{\circ} \mathrm{C}$ for 15 min. After the incubation period, reactions were spun through a $100 \mathrm{kDa}$ centrifugal device that retains the $\mathrm{YjeQ}$ protein or its variants only when bound to the ribosomal particles. The unbound fraction of protein was captured in the flow-through. However, the protein bound to the $30 \mathrm{~S}$ subunits was retained by the filter and subsequently resuspended. Resolving these samples by SDS-PAGE allowed us to visualize the content of the flow-through and bound fractions (Fig. 1).

In this assay, one of the factors affecting the amount of binding of $\mathrm{YjeQ}$ to the $30 \mathrm{~S}$ subunits is the salt concentration in the reaction buffer. Filtration assays (Supplemental Fig. S3; left panel) performed with buffers containing a concentration of $\mathrm{NH}_{4} \mathrm{Cl}$ ranging from 60 to $600 \mathrm{mM}$ showed that at $300 \mathrm{mM} \mathrm{NH}_{4} \mathrm{Cl}$, YjeQ bound to the $30 \mathrm{~S}$ subunit at $\sim 1: 1$ ratio, which is the stoichiometry that has been previously established for the 30S+YjeQ complex (Daigle and Brown 2004; Himeno et al. 2004; Guo et al. 2011; Jomaa et al. 2011b).
Therefore, we used buffer containing $300 \mathrm{mM} \mathrm{NH}_{4} \mathrm{Cl}$ for these filtration assays, as these conditions were optimal to measure specific binding of YjeQ to the $30 \mathrm{~S}$ subunits and minimize any potential nonspecific binding. Under these conditions the filter did not retain $\mathrm{YjeQ}$ or the $\mathrm{YjeQ}$ protein variants when they were by themselves, thus they all appeared in the flow through upon centrifugation. Instead, the filter retained all the mature and immature $30 \mathrm{~S}$ subunits (Fig. 1A).

Under these conditions, we first tested the ability of fulllength YjeQ to bind the mature and immature 30S subunits and found that the protein bound equally well to both particles in the presence of GMP-PNP (Fig. 1B). Then, we tested the binding of the YjeQ variants to the mature $30 \mathrm{~S}$ subunit (Fig. 1B, top panel). We found that the YjeQ M1 variant lacking the entire zinc-finger domain showed a fourfold decrease in binding to the mature $30 \mathrm{~S}$ subunit compared with wildtype YjeQ. Similarly, the YjeQ M2 variant, containing only the first $3^{10}$-helix of the zinc-finger domain, showed a fivefold decrease in binding. However, the YjeQ M3 variant that had only missing the carboxy-terminal $\alpha$-helix motif showed slightly improved binding compared with wild-type YjeQ (Fig. 1B, top panel).

A caveat in the filtration assay was that not all of YjeQ M3 protein was recovered in the flow-through nor in the bound fractions. This suggested that a percentage of the YjeQ M3 protein was nonspecifically binding to the filter, despite stringent blocking of the filter with solution of bovine serum albumin (BSA). To confirm the ability of the YjeQ M3 variant to bind the mature $30 \mathrm{~S}$ subunit a pelleting assay was performed with both proteins (Fig. 1C). In the pelleting assay, the binding reaction was laid over a sucrose cushion in the same buffer conditions used for the filtration assay and then subjected to ultracentrifugation. Protein binding to the $30 \mathrm{~S}$ subunit was found in the pellet fraction and the unbound protein was found in the supernatant fraction. Proteins in both fractions were then visualized by SDSPAGE. Consistent with the filtration assay (Fig. 1C), the pelleting assay showed that the binding of YjeQ M3 to the mature 30 S subunit was $\sim 1.5$-fold enhanced compared to that of wild-type YjeQ (Fig. 1C). Considering that the stoichiometry of the $30 \mathrm{~S}+\mathrm{YjeQ}$ complex is 1:1, these results suggest that under the salt concentration used in the pelleting experiment $\left(300 \mathrm{mM} \mathrm{NH}_{4} \mathrm{Cl}\right.$ ) approximately one-third of the YjeQ M3 variant was binding the mature $30 \mathrm{~S}$ subunit in an unspecific manner. It is plausible that exposure of a new surface in the zinc-finger domain of YjeQ upon removal of the carboxy-terminal $\alpha$-helix may be causing the unspecific binding.

When analyzing the binding of the YjeQ variants to the immature subunit, the binding of the YjeQ M1 and YjeQ M2 variants only decreased by approximately twofold when compared with wild-type YjeQ. In the case of YjeQ M3, it bound to the immature $30 \mathrm{~S}$ subunit similarly to wild-type YjeQ (Fig. $1 \mathrm{~B}$, bottom panel).

Overall, this data suggest that the zinc-finger domain plays an important role for efficient binding of $\mathrm{YjeQ}$ to the mature 
A

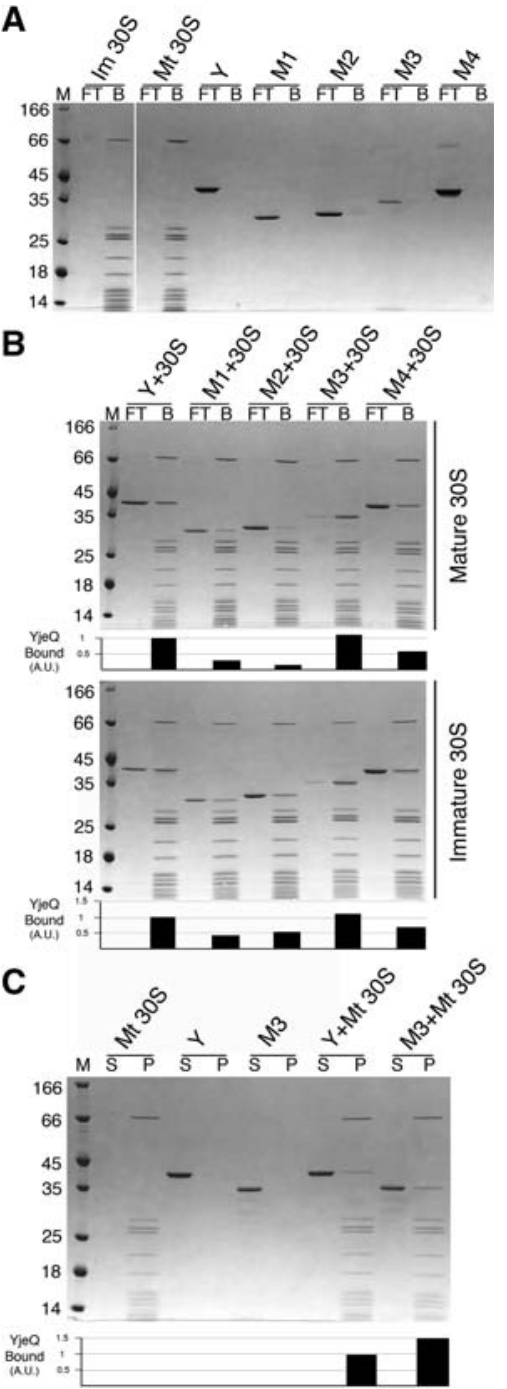

FIGURE 1. Binding of YjeQ carboxy-terminal variants to the mature and immature $30 \mathrm{~S}$ subunits. $(A, B)$ Ability of $\mathrm{YjeQ}(\mathrm{Y})$ and $\mathrm{YjeQ}$ variants (M1, M2, M3, and M4) to bind to the mature (Mt) and immature (Im) $30 \mathrm{~S}$ subunits analyzed by filtration assays. Coomassie blue stained SDSPAGE in A contains the controls for the experiment consistent in reactions containing either YjeQ (full-length or variants) or 30S subunits (mature or immature) by themselves. Reactions containing a mixture of YjeQ protein and ribosomal particles contained a fivefold molar excess of protein. Assembly mixtures were incubated for $15 \mathrm{~min}$ at $16^{\circ} \mathrm{C}$ in the presence of $1 \mathrm{mM}$ GMP-PNP. Following incubation, the reactions were passed through a $100 \mathrm{kDa}$ cut-off filter using centrifugation. The unbound protein was captured in the flow-through (FT) and the protein bound to the ribosomal particles (B) was retained by the filter and resuspended by an equal volume of buffer. The molecular weight marker (M) is in $\mathrm{kDa}$. The flow-through and bound portions from these assays were loaded into $4 \%-12 \%$ bis-tris polyacrylamide gels and resolved using SDS-PAGE. (C) Pelleting assay of YjeQ M3 variant with the mature $30 \mathrm{~S}$ subunit. A fivefold excess of YjeQ M3 was incubated with mature $30 \mathrm{~S}$ subunits for $15 \mathrm{~min}$ at $16^{\circ} \mathrm{C}$. Following the incubation, reactions were laid over a sucrose cushion and subjected to ultracentrifugation. Proteins that were unbound were collected in the supernatant (S), while proteins that bound to the $30 \mathrm{~S}$ particle were found in the pellet $(\mathrm{P})$. The molecular weight $(\mathrm{M})$ is in $\mathrm{kDa}$. The pellet and supernatant were resolved by $4 \%-12 \%$ bis-tris SDS-PAGE and stained with Coomassie blue. The bar diagrams under the gels in $B$ and $C$ indicate the binding of the $\mathrm{YjeQ}$ variants to the $30 \mathrm{~S}$ subunits with respect to wild-type $\mathrm{YjeQ}$ (set as 1 ).
$30 \mathrm{~S}$ subunit, but does not require the carboxy-terminal $\alpha$-helix for this function. It also suggests that the zinc-finger domain may not play as critical as a role for binding to the immature $30 \mathrm{~S}$ subunit. In this case, efficient binding to the subunit seems to depend more on the OB-fold domain.

\section{Lysine 298 and arginine 300 in the carboxy-terminal zinc-finger domain of $\mathrm{YjeQ}$ are not essential for binding to the mature $30 \mathrm{~S}$ subunit}

A previous structural study describing the cryo-EM structure of the mature 30S subunit in complex with YjeQ (Guo et al. 2011) indicates that $Y j e Q$ binds in an orientation in which the OB-fold domain interacts with helix 44 and the zinc-finger domain interacts with the head of the 30 S subunit mainly through residues Lys 298 and Arg 300 (Fig. 5A, below). The electrostatic interactions between the positively charged side chains of these two amino acids and the negatively charged phosphate groups of the 16S rRNA of the ribosomal particle stabilize these contacts. To study the contribution of Lys 298 and Arg 300 for binding of YjeQ to the ribosome subunit, we mutated both residues to alanine in the full-length YjeQ protein to produce the YjeQ M4 variant (Supplemental Fig. S1B). In the precipitation test this mutant did not show any instability when exposed at $37^{\circ} \mathrm{C}$ (Supplemental Fig. $\mathrm{S} 1 \mathrm{C}$ ) and its CD spectra at all temperatures tested completely overlapped with that of wild-type YjeQ (Supplemental Fig. S2) indicating that the YjeQ M4 variant folds into its native conformation. When we tested the ability of the YjeQ M4 variant to bind the mature and immature $30 \mathrm{~S}$ subunit (Fig. $1 \mathrm{~A}, \mathrm{~B})$, we found that the YjeQ M4 variant had only decreased binding to the mature and immature 30S subunits by twofold and 1.3 -fold, respectively. This result indicated, contrary to what the cryo-EM structure suggested (Guo et al. 2011), that residues Lys 298 and Arg 300 in the zinc-finger domain of YjeQ are not essential for binding to the mature $30 \mathrm{~S}$ subunit.

\section{The carboxy-terminal $\alpha$-helix of the zinc-finger domain is necessary for the $30 \mathrm{~S}$ subunit-dependent GTPase activity of $\mathrm{YjeQ}$}

In the absence of ribosome subunits YjeQ hydrolyzes GTP slowly and exhibits a $k_{\text {cat }}$ of $9.4 \mathrm{~h}^{-1}$ and a $K_{\mathrm{m}}$ for GTP of $120 \mu \mathrm{M}$ (Daigle et al. 2002). However, association with the $30 \mathrm{~S}$ subunit results in a 160 -fold stimulation of YjeQ GTPase activity. Previous studies indicated that the first 20 amino-terminal amino acids are important for ribosomestimulated GTPase activity of YjeQ (Daigle and Brown 2004).

Here, we tested the carboxy-terminal truncations of YjeQ to determine whether the zinc-finger domain plays any role in this activity. The initial rates of GTP hydrolysis for fulllength YjeQ and YjeQ variants were measured in the presence and absence of mature and immature $30 \mathrm{~S}$ subunits. To this end we used a malachite green assay to measure the amount 
of free phosphate produced in the reaction from GTP hydrolysis. Reactions were incubated for $1 \mathrm{~h}$ at $25^{\circ} \mathrm{C}$ before they were quenched. This temperature was chosen instead of the $30^{\circ} \mathrm{C}$ that was used in previous studies (Daigle and Brown 2004) with $Y j e Q$, to ensure that the $Y j e Q$ variants remained stable during the course of the reaction (Supplemental Figs. S1C, S2). The initial rate of the GTP hydrolysis was estimated from the amount of free phosphate produced in each reaction.

We found that all the carboxy-terminal truncation variants of YjeQ exhibited an intrinsic initial rate of GTP hydrolysis comparable to full-length YjeQ and that ranged from 1-4 $\mathrm{pmol} / \mathrm{min}$ (Fig. 2). When the mature $30 \mathrm{~S}$ subunit was included in the reaction, the initial rate of the full-length YjeQ increased by approximately eightfold (see Materials and Methods). However, it did not increase considerably for any of the carboxy-terminal variants of $\mathrm{YjeQ}$, except for the YjeQ M4 variant that showed an initial rate comparable to wild-type YjeQ. Using the immature 30 S subunit in the reactions caused less than a threefold increase in the initial rate of full-length YjeQ, but again no increase was observed for the YjeQ variants (Fig. 2). This result is consistent with previous work (Himeno et al. 2004) that show the stimulation of the YjeQ GTPase activity by the immature $30 \mathrm{~S}$ subunits is minimal in comparison to the mature $30 \mathrm{~S}$ subunit. However, the fold-increase in the initial rate measured for the full-length protein was substantially lower than the 160 -fold stimulation that had been reported (Daigle and Brown 2004). This difference is likely caused by the lower temperature $\left(25^{\circ} \mathrm{C}\right.$ versus $30^{\circ} \mathrm{C}$ ) incubations in our assays.

Considering these results, we interpreted that the YjeQ M1 and YjeQ M2 variants did not show an increased level in 30S subunit-dependent GTPase activity (Fig. 2), possibly because both proteins cannot efficiently bind the mature $30 \mathrm{~S}$ particle (Fig. 1B). In addition, we found that YjeQ M3 was able to bind the mature $30 \mathrm{~S}$ subunit, but showed no increase in $30 \mathrm{~S}$ subunit-dependent GTPase activity (Fig. 2). These results

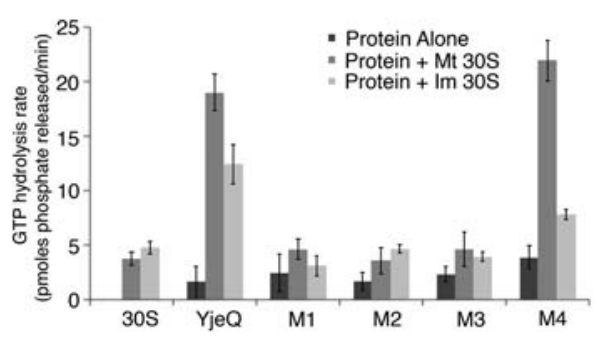

FIGURE 2. Stimulation of GTPase activity of YjeQ variants by mature and immature $30 \mathrm{~S}$ subunits. The GTP hydrolysis rate of the YjeQ variants alone or in the presence of mature (Mt 30S) and immature $30 \mathrm{~S}$ (Im 30S) subunits was assessed using the Malachite Green Phosphate assay as described in Materials and Methods. The GTPase hydrolysis rates plotted in the graph were determined by measuring the free phosphate produced after the reactions had been incubated for $60 \mathrm{~min}$ at $25^{\circ} \mathrm{C}$. Standard deviations shown in the plot correspond to three replicas of the experiment. indicate that while the carboxy-terminal $\alpha$-helix in the zincfinger domain is not required for binding, it is a necessary motif for stimulation of GTP hydrolysis by the $30 \mathrm{~S}$ subunit.

\section{YjeQ promotes the release of RbfA from the mature 30S subunit through the carboxy-terminal $\alpha$-helix of the zinc-finger domain}

Genetic and biochemical studies suggest that a function of YjeQ during maturation of the $30 \mathrm{~S}$ subunit is assisting on the release of RbfA from the mature $30 \mathrm{~S}$ subunit once the maturation of the particle is completed (Goto et al. 2011). It is not understood how this functional interplay is implemented and the structural determinants in YjeQ that allow the protein to perform this action. Prompted by the interesting phenotype of the YjeQ M3 variant that binds the 30 S subunit without having an increase in its GTPase activity, we tested the ability of this $\mathrm{YjeQ}$ variant to remove RbfA and determined whether the CTE has any role in this activity.

To test the YjeQ M3 variant, we first modified the filtration assay to visualize the displacement of RbfA by full-length YjeQ. In these experiments, RbfA was first bound to the ribosomal subunits by incubating the reaction for $15 \mathrm{~min}$. YjeQ was then added and incubated for an additional $15 \mathrm{~min}$ before the reaction was spun in the centrifugal device to separate free protein from that bound to the $30 \mathrm{~S}$ subunits. The content in the flow through and bound portion was then analyzed by SDS-PAGE.

As in the assays testing the binding of YjeQ (Fig. 1B), the concentration of $\mathrm{NH}_{4} \mathrm{Cl}$ in the buffer is a critical parameter influencing the binding of RbfA to the small ribosome subunits. Performing the assembly reactions in buffers containing a range of $\mathrm{NH}_{4} \mathrm{Cl}$ concentration from 60 to $600 \mathrm{mM}$, we determined that at $60 \mathrm{mM} \mathrm{NH}_{4} \mathrm{Cl}$, RbfA bound stoichiometrically to the immature 30S subunit (Supplemental Fig. S3, right panel). Binding of RbfA to immature $30 \mathrm{~S}$ subunits is better than to mature $30 \mathrm{~S}$ subunits (Goto et al. 2011), therefore this analysis was done with immature particles. In the case of mature $30 \mathrm{~S}$ subunits, binding of RbfA is substoichiometric in buffer containing $60 \mathrm{mM} \mathrm{NH}_{4} \mathrm{Cl}$ (Supplemental Fig. S4A, middle panel). Consequently, the $\mathrm{NH}_{4} \mathrm{Cl}$ concentration in these assays aiming to visualize the release of RbfA upon binding of $\mathrm{YjeQ}$ was maintained at $60 \mathrm{mM}$ $\mathrm{NH}_{4} \mathrm{Cl}$, ensuring that binding of RbfA to the mature 30S subunit was still occurring (Supplemental Fig. S4, middle panel). We found that under these conditions YjeQ was able to efficiently remove RbfA from the mature $30 \mathrm{~S}$ subunit. The removal of RbfA was very efficient in the presence of GTP $(\sim 95 \%)$ and GMP-PNP ( $90 \%)$. In the presence of GDP, YjeQ displaced $\sim 65 \%$ of the RbfA bound to the mature 30 S subunit (Supplemental Fig. S4A, middle panel).

In the case of immature $30 \mathrm{~S}$ subunits, $\mathrm{YjeQ}$ could not release RbfA from the immature particle, regardless of the nucleotide present in the buffer (Supplemental Fig. S4A, bottom panel). To establish that the inability of YjeQ to release RbfA 
from the immature 30 S subunit was not due to the low salt concentration on the buffer, this experiment was repeated also at higher salt concentration (Supplemental Fig. S4B). In this case the assembly reaction was carried out in the presence of GMP-PNP. We found that YjeQ still did not displace RbfA from the immature 30S subunits, even at the high salt concentrations and in the presence of GMP-PNP. Control filtration assays performed in parallel using YjeQ, RbfA, or both proteins in low or high salt buffer, showed that the filter did not retain the proteins by themselves or when combined in either buffer (Supplemental Fig. S4A, top panel; Supplemental Fig. S4B, left gel).

Now that a reliable assay was in place to visualize displacement of RbfA from the 30S subunit upon YjeQ binding, we tested the ability of the YjeQ M3 variant to perform this action. In this case, reactions were incubated at $25^{\circ} \mathrm{C}$ in order to maintain the solubility and folding of the YjeQ variant. Subsequently, the reaction was spun in a centrifugal device to perform the filtration assay. Interestingly, we found that whereas wild-type YjeQ removed $100 \%$ of the RbfA bound to the mature $30 \mathrm{~S}$ subunit, the YjeQ M3 variant enhanced binding of RbfA by fourfold instead of removing it (Fig. $3 \mathrm{~A})$. Consistently with this result, when the reactions were laid over a sucrose cushion and subjected to a pelleting assay we observed a similar result (Fig. 4B). Wild-type YjeQ removed $\sim 60 \%$ of the RbfA bound to the mature $30 \mathrm{~S}$ subunit and the YjeQ M3 variant increased binding of RbfA by 5.5fold. These results indicate that the carboxy-terminal $\alpha$-helix in the zinc-finger domain is the structural motif implementing the ability of YjeQ to remove RbfA from the 30S subunit once the maturation is completed. Furthermore, binding of the YjeQ M3 variant lacking the carboxy-terminal $a$-helix seemed to induce a conformation in the mature $30 \mathrm{~S}$ subunit that stabilized the binding of RbfA.

\section{The carboxy-terminal extension of the zinc-finger domain in YjeQ is necessary for its function in vivo}

The in vitro experiments described above indicated that the carboxy-terminal $a$-helix in the zinc-finger domain is an essential element for the 30 S subunit-dependent GTPase activity of YjeQ (Fig. 2), as well as for YjeQ to promote on the release of RbfA once the maturation of the $30 \mathrm{~S}$ subunit is completed (Fig. 3). To test whether the carboxy-terminal a-helix is necessary for YjeQ to assist in the assembly of the 30 S subunits in vivo, we performed a complementation assay by expressing the YjeQ M3 variant in the yjeQ null strain. These cells were then tested for growth, rRNA and ribosome content. The wild-type yjeQ or yjeQ $m 3$ genes in these experiments were reintroduced in the null strain with a high-copy plasmid in which the expression is under the control of an IPTG-inducible T5 promotor (Kitagawa et al. 2005). Reintroduction of the gene in a plasmid, instead of in the chromosome eliminated the possibility of polar effects on downstream genes.
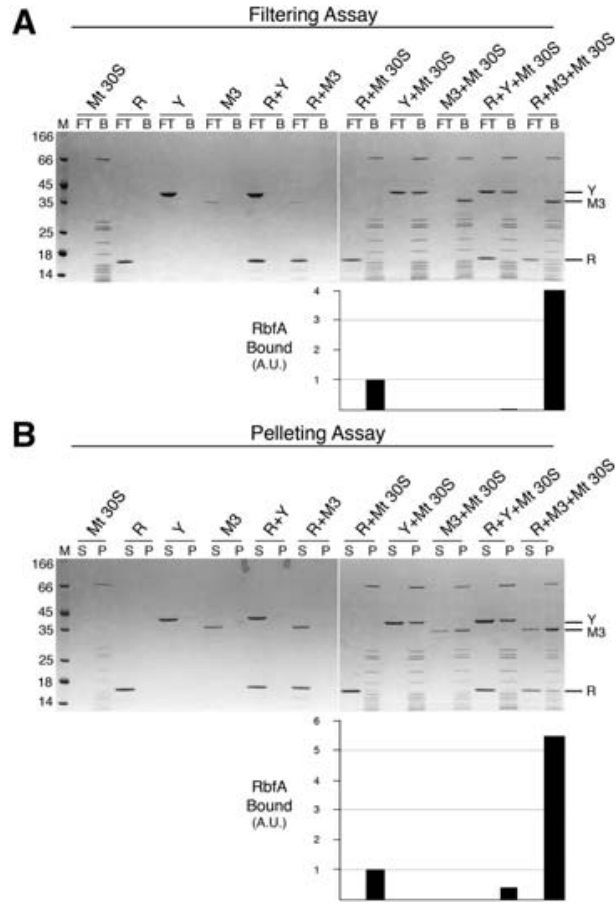

FIGURE 3. YjeQ M3 is unable to remove RbfA bound to the mature $30 \mathrm{~S}$ subunit. (A) Filtration assay to test the release of RbfA (R) from the mature $30 \mathrm{~S}$ subunit (Mt 30S) in the presence of YjeQ wild-type (Y) and YjeQ M3 variant (M3). These reactions were performed by adding the assembly factors in fivefold molar excess with respect to the $30 \mathrm{~S}$ subunits and in the presence of GMP-PNP. Incubations were done at $25^{\circ} \mathrm{C}$. Flow-through (FT) and bound (B) fractions from the filtration assay were resolved in $4 \%-12 \%$ bis-tris SDS-PAGE and stained with Coomassie blue. (B) Pelleting assay of identical reactions used in $A$. The molecular weight marker $(\mathrm{M})$ is in $\mathrm{kDa}$. Supernatant $(\mathrm{S})$ and pellet (P) fractions from this assay were resolved in $4 \%-12 \%$ bis-tris SDSPAGE and stained with Coomassie blue. The bar diagrams under the gels indicate the binding of the RbfA to the mature $30 \mathrm{~S}$ subunit in each reaction. The observed binding of RbfA to the mature $30 \mathrm{~S}$ subunit was defined as 1 .

To analyze the growth, cells were grown at $25^{\circ} \mathrm{C}$ for up to $47 \mathrm{~h}$ and their optical density was measured and plotted over time (Fig. 4A). We also calculated their growth rate (Table 1). As previously described (Campbell et al. 2006; Goto et al. 2011) the E. coli yjeQ null strain exhibited a slow-growth phenotype (growth rate $[\mathrm{GR}]=0.14 \mathrm{~h}^{-1}$ ) compared to the parental strain $\left(\mathrm{GR}=0.44 \mathrm{~h}^{-1}\right)$. We found that expression of wild-type YjeQ in small amounts achieved by using a low concentration $(1 \mu \mathrm{M})$ of IPTG was sufficient to partially correct the slow-growth phenotype of the null yjeQ strain $(\mathrm{GR}=$ $0.21 \mathrm{~h}^{-1}$ ). However, overexpression of YjeQ by using a higher concentration of IPTG $(100 \mu \mathrm{M})$ led the cells to grow slower than the null strain $\left(\mathrm{GR}=0.12 \mathrm{~h}^{-1}\right)$. This was likely the result of the toxic effect caused by an excess of YjeQ in the cells, which causes $70 \mathrm{~S}$ subunits to dissociate (Daigle and Brown 2004; Himeno et al. 2004). Consequently to prevent the toxicity effects due to high levels of expression of YjeQ, the complementation experiments with the YjeQ M3 variant were performed using low concentrations of IPTG. Expression 

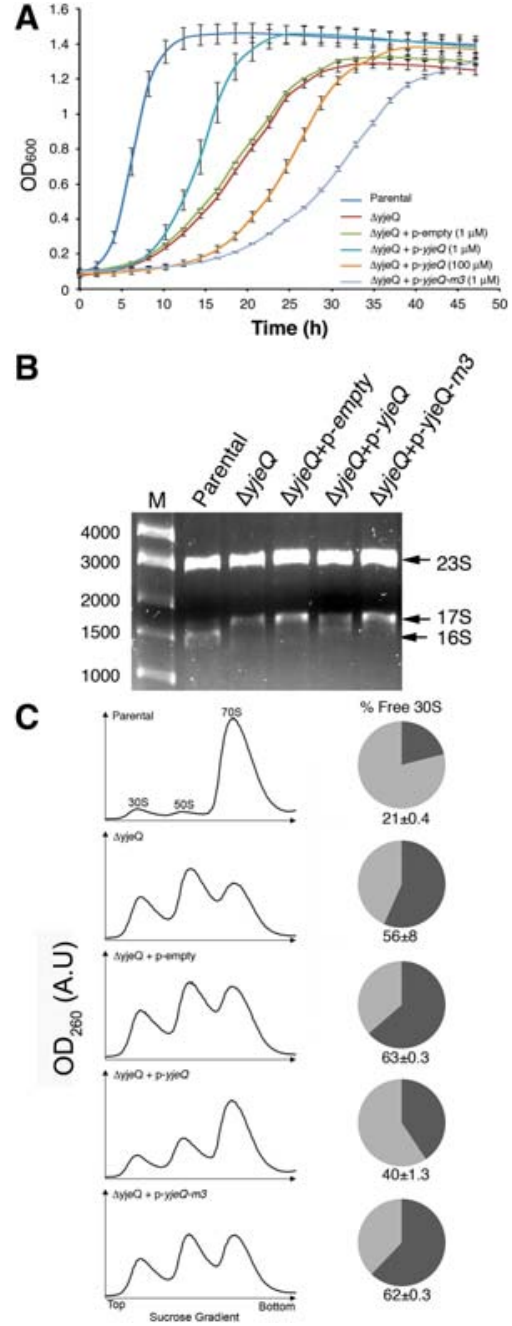

FIGURE 4. The carboxy-terminal extension of the zinc-finger domain in YjeQ is necessary for its function in vivo. $(A)$ The parental strain and the $y j e Q$ null strain by itself or complemented with the plasmid expressing yjeQ, YjeQ M3 variant, or the empty vector were induced at $t=0 \mathrm{~h}$ with the indicated concentration of IPTG and grown at $25^{\circ} \mathrm{C}$ for $47 \mathrm{~h}$. Growth was monitored by measuring absorbance at $600 \mathrm{~nm}$ and plotted against time. Standard deviations shown in the plot correspond to three replicas of the experiment. (B) Total rRNA of cell cultures were analyzed when cultures reached mid-log phase represented by $\mathrm{OD}_{600}$ $=0.2$. Total rRNA was extracted and resolved by electrophoresis in $0.9 \%$ synergel $-0.7 \%$ agarose gel. The marker $(\mathrm{M})$ is in base pairs. $(C)$ Ribosome absorbance profiles from the parental strain and yjeQ null strain by itself or complemented with the plasmid expressing YjeQ, YjeQ M3 variant, or the empty plasmid were fractionated by ultracentrifugation in 10\%-30\% sucrose gradients providing the profiles shown in this panel. Peaks for the 30S, 50S subunits, and 70S ribosomes are indicated. The proportion of free $30 \mathrm{~S}$ to bound $30 \mathrm{~S}$ (i.e., $30 \mathrm{~S}$ subunits in $70 \mathrm{~S}$ complexes) in each case was calculated by integrating the areas under the $30 \mathrm{~S}$ and $70 \mathrm{~S}$ peaks of the sucrose gradient profiles. The area of the $30 \mathrm{~S}$ peak plus one-third the area of the $70 \mathrm{~S}$ peak corresponds to the total $30 \mathrm{~S}$ population. The area of the $30 \mathrm{~S}$ peak was divided by the total $30 \mathrm{~S}$ absorbance to obtain the percentage of free $30 \mathrm{~S}$ subunits and produce the pie charts in this panel. The standard deviations shown correspond to three replicas of the experiment. Peak area for the $30 \mathrm{~S}$ subunit in each case was measured with respect to the area under the $70 \mathrm{~S}$ peak to calculate the percentage of free $30 \mathrm{~S}$ subunits in both strains. The calculated percentages are shown in the pie charts. The standard deviations shown correspond to three replicas of the experiment. of the YjeQ M3 variant in this manner caused the cells to exhibit a growth rate of $0.10 \mathrm{~h}^{-1}$, which is even slower than that shown by the null yjeQ strain. In the control experiments where cells were transformed with the empty vector we found that it had no effect on the growth rate of the null strain (Fig. 4A; Table 1).

Total rRNA from the cells tested for growth was purified and resolved by gel electrophoresis (Fig. 4B) after they had been grown to mid-log phase. We found that the majority of the rRNA purified from parental cells was mature 16S rRNA, as opposed to the null yjeQ cells (alone or transformed with the empty plasmid), which mainly contained precursor $17 \mathrm{~S}$ rRNA. Cells complemented with the plasmid expressing wild-type YjeQ showed that $~ 50 \%$ of the accumulated rRNA had been processed into $16 \mathrm{~S}$ rRNA. Conversely, in the cells expressing the YjeQ M3 variant most of the rRNA remained as unprocessed immature 17S rRNA (Fig. 4B).

Finally, we analyzed the ribosome profiles of the parental, null yjeQ cells and cells complemented with either the empty plasmid or that encoding wild-type YjeQ or the YjeQ M3 variant (Fig. 4C). The parental strain produced the expected profile with most of the particles assembled as 70S ribosomes and two small peaks representing dissociated 30 S and 50S subunits. In these cells only $\sim 21 \%$ of the total 30 S subunits were free and not associated with the 50S subunit. Null yjeQ cells and cells transformed with the empty plasmid produced a profile in which $56 \%$ and $63 \%$, respectively, of the total $30 \mathrm{~S}$ subunits did not associate to form $70 \mathrm{~S}$ ribosomes (Daigle and Brown 2004; Himeno et al. 2004). Complementation with the plasmid expressing YjeQ caused the proportion of free $30 \mathrm{~S}$ subunits to decrease to $40 \%$. However, the percentage of free $30 \mathrm{~S}$ subunits in cells expressing the YjeQ M3 was even higher $(62 \%)$ than that of the null yjeQ cells. Therefore, we concluded from the analysis of the growth, rRNA, and ribosomal content that in vivo the YjeQ M3 variant was not able to complement the slow-growth phenotype exhibited by null yjeQ cells. Indeed, the observed phenotypes suggest that YjeQ M3 exhibited a gain-of function that is toxic most likely due to its enhanced binding to the $30 \mathrm{~S}$ subunit and its ability to promote binding of RbfA (instead of facilitating release). Tighter binding of YjeQ and RbfA combined most

TABLE 1. Growth rates of the E. coli yjeQ null strain in the YjeQ and YjeQ-M3 variant complementation assay

\begin{tabular}{lr}
\hline E. coli strains & Growth rate $k=\ln 2 / \mathrm{D} T$ \\
\hline Parental & $0.44 \pm 0.01$ \\
$\Delta y j e Q$ & $0.14 \pm 0.01$ \\
$\Delta y j e Q+$ p-empty $(1 \mu \mathrm{M}$ IPTG $)$ & $0.14 \pm 0.01$ \\
$\Delta y j e Q+$ p-yjeQ $(1 \mu \mathrm{M}$ IPTG & $0.21 \pm 0.01$ \\
$\Delta y j e Q+$ p-yjeQ $(100 \mu \mathrm{M}$ IPTG $)$ & $0.12 \pm 0.01$ \\
$\Delta y j e Q+$ p-yje-m3 (1 $\mu \mathrm{M}$ IPTG $)$ & $0.10 \pm 0.01$
\end{tabular}

Standard deviations were calculated from three replicas of the experiment. 
likely impaired proper association of the 30 S subunits with the $50 \mathrm{~S}$ subunits to form $70 \mathrm{~S}$ ribosomes. Consistently, we observed that the proportion of the free $30 \mathrm{~S}$ subunits in the null yjeQ cells transformed with the plasmid expressing the YjeQ M3 was higher than that of the nontransfected null yjeQ cells.

\section{DISCUSSION}

In this study, we found that the carboxy-terminal zinc-finger domain in YjeQ is important for the overall structural stability of the protein. Interestingly, an in silico analysis of other circularly permutated GTPases (Anand et al. 2006) concluded that a consequence of repositioning the G3/switch II motif within the GTPase domain is that an anchoring carboxy-terminal domain is then required to fasten switch II and maintain its efficiency for GTP binding and hydrolysis. Our finding that the carboxy-terminal zinc-finger domain is necessary for the stability of YjeQ is consistent with this model.

In addition, we also determined that the zinc-finger domain of $\mathrm{YjeQ}$ is essential for the role of this protein in assisting the late stages of maturation of the $30 \mathrm{~S}$ subunit. The presented data indicate that this domain is subdivided into two functional motifs. The part of the domain coordinating the zinc ion is the region that allows for efficient binding of the protein to the $30 \mathrm{~S}$ subunit, whereas the carboxy-terminal a-helix is the region through which YjeQ senses the binding to the mature 30S subunit triggering GTP hydrolysis in the GTPase domain. The zinc-finger domain is attached to the GTPase domain through the switch II region, which propagates the conformational change. In addition, the carboxyterminal $\alpha$-helix is also the region that implements the functional interplay of YjeQ with RbfA and facilitates the removal of RbfA from the mature $30 \mathrm{~S}$ subunit once maturation of the 30 S subunit is completed (Goto et al. 2011).

Recent structural studies with immature 30 S subunits purified at late stages of assembly (Guo et al. 2011, 2013; Jomaa et al. 2011b; Boehringer et al. 2012; Clatterbuck Soper et al. 2013; Leong et al. 2013; Yang et al. 2014) revealed that the decoding center is the last region to fold into the mature conformation during the assembly of the subunit. Multiple assembly factors, including YjeQ, RbfA, RimM, and Era, bind to this region (Sharma et al. 2005; Datta et al. 2007; Guo et al. 2011; Jomaa et al. 2011b) at the late stages of assembly and operate in conjunction to monitor the proper folding of this region and prevent immature $30 \mathrm{~S}$ subunits from engaging in translation. During this process functional interplays between assembly factors likely occur. In principle, any of the maturation steps these proteins facilitate including rRNA folding, rRNA processing, or mediating protein-RNA interactions could be assisted by several of these proteins simultaneously, rather than by protein factors individually. In addition, functional interplays likely play an important role in ensuring that all of the assembly factors are released once the maturation process is completed. Factor release is essential for the mature 30S subunit to enter the pool of actively translating ribosomes (Shajani et al. 2011).

Although there is genetic, biochemical, and structural evidence suggesting a functional interplay between these four putative assembly factors, the specific mechanism on how they work together to assist in maturation of the decoding center remains to be described. Recently, a study (Goto et al. 2011) identified that one of the functions of YjeQ is to assist in the release of RbfA once the maturation of the 30S subunit has been completed. However, it is still not understood how this functional interplay between the two proteins is implemented. A costructure of the $30 \mathrm{~S}$ subunit in complex with both YjeQ and RbfA that could be informative about this mechanism has not yet been obtained. Furthermore, the cryo-EM structures of the YjeQ protein in complex with the mature 30S subunit (Guo et al. 2011; Jomaa et al. 2011b) propose two conflicting binding orientations of YjeQ to the 30 S subunit. Therefore, an unambiguous functional model from these structural data cannot be derived.

In this study, we found that the part of the domain coordinating the zinc ion in YjeQ is important for binding to the $30 \mathrm{~S}$ subunit and the carboxy-terminal $\alpha$-helix is essential for this factor to facilitate the release of RbfA from the mature 30S subunit. An important question is how these findings conform to the two conflicting cryo-EM structures (Guo et al. 2011; Jomaa et al. 2011b). The two cryo-EM structures showed that YjeQ binds to the $30 \mathrm{~S}$ subunit covering the region of helix 44 forming the decoding center and also contacts the head and nearby region of the platform of the ribosomal particle (Fig. 5A,B). However, the two structures proposed a different orientation of the YjeQ protein in this complex. One of the structures (Guo et al. 2011) placed YjeQ with the OB-fold and GTPase domain contacting helix 44 and the carboxy-terminal zinc-finger domain interacting with the head (Fig. 5A, left panel). The second structure (Jomaa et al. 2011b) places YjeQ in an orientation rotated by $\sim 180^{\circ}$ around an axis perpendicular to the interface surface of the $30 \mathrm{~S}$ subunit. In this structure, the OB-fold domain is the region interacting with the platform and the carboxyterminal zinc-finger domain sits in helix 44 (Fig. 5B, left panel).

Analysis of the two structures revealed that the data presented here are difficult to reconcile with the cryo-EM map where the zinc-finger domain contacts the head domain (Guo et al. 2011). According to this model, only three amino acids within the loop coordinating the zinc ion are close enough to interact with the phosphate-oxygen backbone of the rRNA in the head of the 30S subunit (Lys 298 and Arg 300) or r-protein S13 (Tyr 299) (Fig. 5A, right panel). In this structure, the rest of the zinc-finger domain, including the carboxy-terminal $\alpha$-helix does not directly contact with either the head or the platform. Only Arg 331 in the carboxy-terminal $a$-helix comes close to the backbone of helix 24 (Fig. 5A, right panel). Our mutational study indicates 


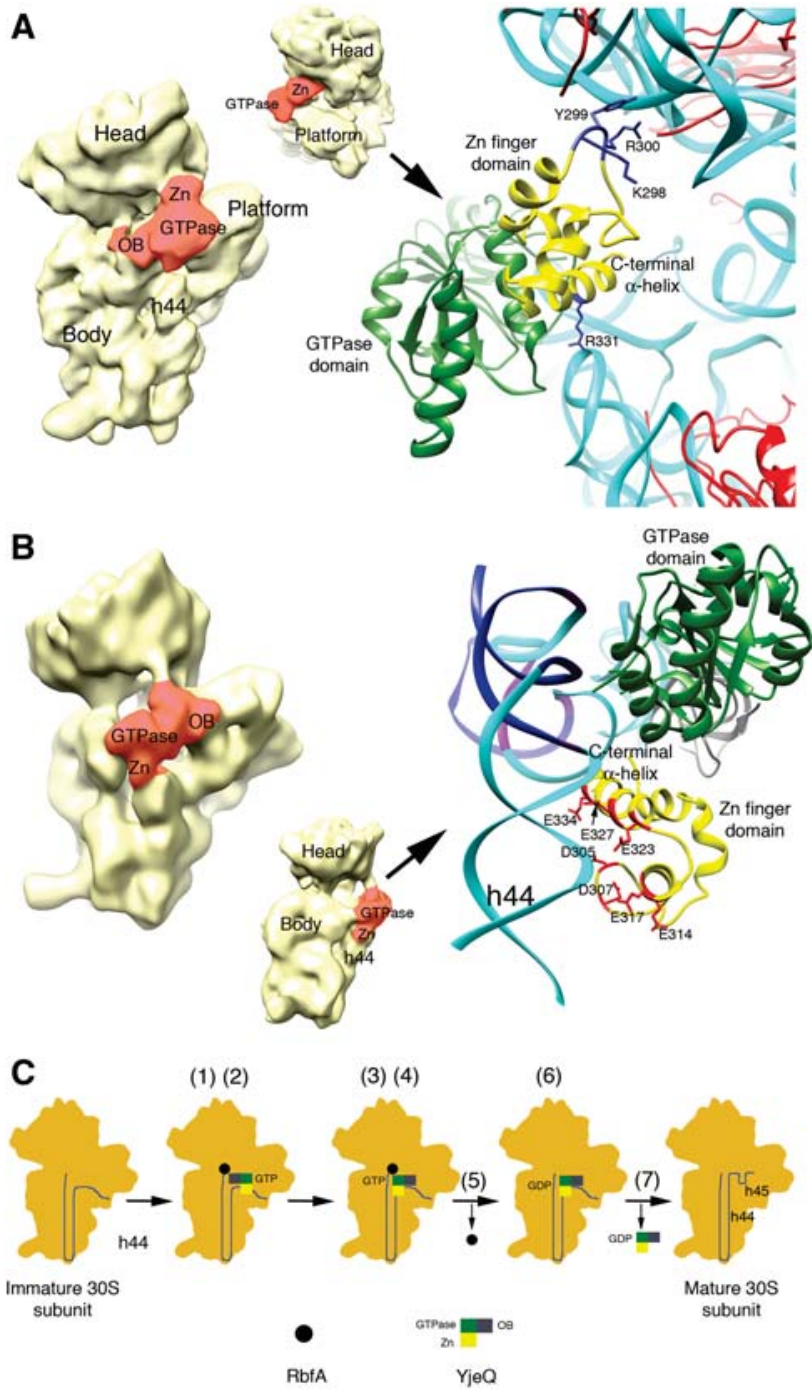

FIGURE 5. Interaction of the zinc-finger domain of $\mathrm{YjeQ}$ with the $30 \mathrm{~S}$ subunit and working model for the functional interplay between YjeQ and RbfA. Structures of the $30 \mathrm{~S}+\mathrm{YjeQ}$ complex as described in Guo et al. (2011) (A) and Jomaa et al. (2011b) (B). The panel in the left shows a view of the entire complex. Landmarks and domains of the $Y j e Q$ protein are labeled. Area colored in red represents the YjeQ protein bound to the $30 \mathrm{~S}$ subunit. The panel in the right shows a zoomed in view of the complex in the area of interaction of the zinc-finger domain with the $30 \mathrm{~S}$ subunit. The rRNA is colored in cyan except for some nucleotides $(B)$ that are colored in dark blue. A corresponding density for these nucleotides does not exist in the cryo-EM map of the 30S+YjeQ complex (Jomaa et al. 2011b). The side chains of important residues for this interaction are labeled. Structures shown were obtained from the EMDB (EMD-1884 and EMD-1895) and PDB (2YKR and 4A2I). Images of the structures were prepared with UCSF Chimera software (Pettersen et al. 2004). (C) Proposed model for the functional interplay between YjeQ and RbfA. The model explains the mechanism through which YjeQ facilitates the release of RbfA once the maturation of the $30 \mathrm{~S}$ subunit is completed. Numbers in brackets refer to the steps of the model described in the text.

that the part of the domain coordinating the zinc ion is essential for YjeQ to bind the mature 30S subunit. Additionally, we found that mutating two (Lys 298 and Arg 300) out of the three residues that come into close contact with the head of the $30 \mathrm{~S}$ subunit did not abolish binding (Fig. 1B). Therefore, it is difficult to envision how the carboxy-terminal $\alpha$-helix could facilitate the release of RbfA from the mature 30S subunit with the zinc-finger domain in this location and having minimal interactions with the ribosome (Fig. 5A, right panel).

In the second cryo-EM structure (Jomaa et al. 2011b), the zinc-finger domain of YjeQ sits in the upper domain of helix 44 near the decoding center (Fig. 5B). In this location, negatively charged residues in the surface of the loop region coordinating the zinc ion and more importantly the carboxyterminal $\alpha$-helix face the negatively charged phosphate-oxygen backbone of nucleotides in helix 44 (Fig. 5B, right panel). This charge distribution in the two motifs of the zinc-finger domain generates electrostatic repulsion with helix 44 causing a displacement of the upper domain of the helix from its mature conformation (Fig. 5B, right panel). It is possible that the carboxy-terminal $\alpha$-helix in YjeQ facilitates the release of RbfA from the mature 30S subunit by preventing the upper domain of helix 44 to adopt the mature conformation.

RbfA binds in the neck region of the 30S subunit (Datta et al. 2007) also causing a displacement of the upper domain of helix 44 and helix 45 . The cryo-EM structure of the $30 \mathrm{~S}$ subunit in complex with RbfA shows that upon binding, these motifs surround RbfA and lock the protein deeply into the cleft between the head and body. Considering that complexes in this cryo-EM study were prepared with a 10to 40 -fold excess of RbfA with respect to the $30 \mathrm{~S}$ subunits (Datta et al. 2007), it is plausible that the conformation visualized by cryo-EM represent a "trapped" state of RbfA bound to the mature $30 \mathrm{~S}$ subunit with the displaced helix 44 and 45 blocking the release of the factor. One of our findings in this study was that substantial binding of YjeQ to the immature $30 S$ subunit is still observed in the absence of the zinc-finger domain (Fig. 1C). Taking all these data into consideration, we propose the following model (Fig. 5C) to explain the functional interplay between $\mathrm{YjeQ}$ and RbfA in mediating the maturation of the decoding center. (1) RbfA first binds in the neck region of the immature $30 \mathrm{~S}$ subunit, which at this point still exhibits the part of helix 44 forming the decoding center in an immature state. (2) RbfA assists in the recruitment of YjeQ, which initially binds to the 30 S subunit largely through the OB-fold domain. (3) As the upper domain of helix 44 continues to fold into its mature state, the region in this helix forming the binding site for the zinc-finger domain of YjeQ adopt the proper conformation to allow YjeQ to bind the $30 \mathrm{~S}$ subunit through both the OB-fold and zinc-finger domains. This is likely the conformation shown by one of the cryo-EM structures (Jomaa et al. 2011b). (4) Binding of YjeQ through the zinc-finger domain to the 30 S subunit prevents the upper domain of helix 44 to fold over the bound RbfA and lock this factor in the "trapped" state shown by the cryo-EM map of the 30S+RbfA complex (Datta et al. 2007). (5) By maintaining the upper domain of helix 44 in 
a non-native conformation, YjeQ facilitates the release of RbfA. (6) Release of RbfA is sensed by the carboxy-terminal a-helix, activating hydrolysis of the GTP molecule bound to YjeQ. (7) The reduced affinity of YjeQ-GDP for the 30S facilitates the dissociation of $\mathrm{YjeQ}$ from the mature subunit through a still uncharacterized mechanism, allowing the upper domain of helix 44 to adopt the conformation observed in the decoding center of the mature subunit. Dissociation of YjeQ also uncovers essential intersubunit bridges (B2a and B3) allowing the mature $30 \mathrm{~S}$ subunit to associate with the $50 \mathrm{~S}$ subunit and engage in protein translation.

An important consideration regarding our experimental set up to analyze the YjeQ-induced release of RbfA is that it does not completely mimic the sequence of events most likely occurring in the cell (Fig. 5C). Mainly, in our assays we bound RbfA directly to the mature $30 \mathrm{~S}$ subunit and then YjeQ was added to test RbfA release. In the cell, it is most likely that RbfA would bind to the immature 30S subunit (instead to the mature $30 \mathrm{~S}$ subunit) and YjeQ-induced release would take place once this subunit has evolved and becomes a mature subunit. Unfortunately, attempts of starting our reactions with the immature $30 \mathrm{~S}$ subunit in complex with RbfA and maturing these subunits in vitro to then test the release of RbfA with YjeQ were unsuccessful. Nevertheless, it is likely that the binding mode of RbfA to the mature 30S subunit in our in vitro assays closely resembles that existing in the analogous complex in vivo. Consequently, conclusions withdrawn from these binding assays most likely apply to the maturation process occurring in vivo. In this regard, future efforts to determine the structure of mature and immature 30 S subunits in complex with RbfA and YjeQ will be important to visualize the conformational changes suggested by the model described above and how the implementation of the functional interplay between YjeQ and RbfA occurs.

\section{MATERIALS AND METHODS}

\section{Cell strains and protein overexpression clones}

Parental Escherichia coli K-12 (BW25113) and E. coli $\Delta y j e Q$ strains were obtained from the Keio collection (Baba et al. 2006).

The pDEST17-yjeQ plasmid used to overexpress wild-type YjeQ protein with an amino-terminal $\mathrm{His}_{6}$ tag cleavable by TEV protease was produced as previously described (Jomaa et al. 2011b). The pDEST17-yjeQM1, pDEST17-yjeQM2, pDEST17-yjeQM3, and pDEST17-yjeQM4 plasmids used to overexpress the YjeQ carboxy-terminal deletion variants were generated by using the QuikChange II XL Site-Directed Mutagenesis Kit (Agilent Technologies). To this end, the parental pDEST17-yjeQ plasmid was used as the template for site-directed mutagenesis reactions that introduced a stop codon in the position of L278 (YjeQM1), F287 (YjeQM2), K320 (YjeQM3) or to create the point mutations K298A and R300A (YjeQM4). The Q5 Site-Directed Mutagenesis Kit (New England Biolabs) was used to produce the pDEST17yjeQM5 plasmid containing mutations C297A and C310A. In this case, we used the same template plasmid as the other mutants.
Overexpression of RbfA was obtained using the pET15b-rbfA plasmid. To produce this plasmid the sequence of the $r b f A$ gene (NCBI reference: NC_007779.1) was optimized for overexpression in $E$. coli cells using the GeneOptimizer software and subsequently synthesized (Life Technologies; Thermo Fisher Scientific) with a NdeI and a BamHI site in the $5^{\prime}$ and $3^{\prime}$ ends of the gene, respectively. The gene was cloned into the carrier pMA-T plasmid using the SfiI and SfiI cloning sites and subsequently subcloned into the final expression vector pET15b using the NdeI and a BamHI restriction sites. The resulting $\mathrm{pET} 15 \mathrm{~b}-\mathrm{rbf} A$ plasmid produces the RbfA protein with an amino-terminal $\mathrm{His}_{6}$ tag cleavable by thrombin.

We used sequencing (MOBIX, McMaster University) to validate all overexpression clones.

\section{Protein overexpression and purification}

Wild-type YjeQ protein and the constructed variants (YjeQ M1, YjeQ M2, YjeQ M3, YjeQ M4, and YjeQ M5) were overexpressed as amino-terminal $\mathrm{His}_{6}$-tag proteins by transforming E. coli BL21A1 cells with the corresponding expression plasmids constructed to produce these proteins (see above). Typically, $1 \mathrm{~L}$ of cells were grown in $\mathrm{LB}$ medium at $37^{\circ} \mathrm{C}$ to an $\mathrm{OD}_{600}$ of 0.6 and expression was induced with $0.2 \% \mathrm{~L}$-arabinose. Wild-type $\mathrm{YjeQ}$ and YjeQ M4 were induced for $3 \mathrm{~h}$ at $37^{\circ} \mathrm{C}$, whereas YjeQ M1, YjeQ M2, and YjeQ M3 were induced for $16 \mathrm{~h}$ at $16^{\circ} \mathrm{C}$ due to the instability and low solubility of the proteins at $37^{\circ} \mathrm{C}$. In the case of the YjeQ $\mathrm{M} 5$ variant, expression was tested at $16 \mathrm{~h}$ at $16^{\circ} \mathrm{C}, 5 \mathrm{~h}$ at $25^{\circ} \mathrm{C}$, and $3 \mathrm{~h}$ at $37^{\circ} \mathrm{C}$. Cells were harvested after induction by centrifugation at $8500 \mathrm{~g}$ for $15 \mathrm{~min}$. The cell pellets were then washed with $1 \times$ PBS buffer (137 mM NaCl, $2.7 \mathrm{mM} \mathrm{KCl,} 8.1 \mathrm{mM} \mathrm{Na}_{2} \mathrm{HPO}_{4}, 1.76$ $\mathrm{mM} \mathrm{KH}_{2} \mathrm{PO}_{4}$ at $\mathrm{pH} 7.4$ ), centrifuged at $1400 \mathrm{~g}$ for $20 \mathrm{~min}$ and resuspended in $20 \mathrm{~mL}$ of lysis buffer $(50 \mathrm{mM}$ Tris- $\mathrm{HCl}$ at $\mathrm{pH} 8.0,10 \%$ $[\mathrm{w} / \mathrm{v}]$ sucrose, $100 \mathrm{mM} \mathrm{NaCl}$ ). The cell suspension was passed through the French press three consecutive times at 20,000 lb/in ${ }^{2}$ to lyse the cells. Lysate was separated from cell debris by centrifugation at $30,000 \mathrm{~g}$ for $40 \mathrm{~min}$ and $\mathrm{NaCl}$ was added to the clarified lysate to bring the concentration to $0.5 \mathrm{M}$. The lysate was then filtered with a $0.45 \mu \mathrm{m}$ filter and loaded onto a HiTrap Metal Chelating column (GE Healthcare Life Sciences) equilibrated with $50 \mathrm{mM}$ Tris- $\mathrm{HCl}$ at $\mathrm{pH} 8.0,0.5 \mathrm{M} \mathrm{NaCl}$ and $5 \%$ [v/v] glycerol. The column was washed with buffer containing concentrations of imidazole of $45 \mathrm{mM}$ and $90 \mathrm{mM}$. Finally, proteins were eluted by increasing the concentration of imidazole in the buffer to $240 \mathrm{mM}$. The purity of fractions was monitored by $15 \%$ SDS-PAGE. Fractions with pure protein were collected and dialyzed overnight at $4^{\circ} \mathrm{C}$ against buffer containing $50 \mathrm{mM}$ Tris- $\mathrm{HCl}$ at $\mathrm{pH} 8.0$ and $5 \%$ [v/v] glycerol. For YjeQ M1, YjeQ M2, and YjeQ M3, the dialysis buffer also included $120 \mathrm{mM}$ $\mathrm{NaCl}$ to increase protein solubility.

The amino-terminal $\mathrm{His}_{6}$-tag was removed by digestion with purified tobacco etch virus (TEV) protease during the previous overnight dialysis step. To this end, $0.05 \mathrm{mg}$ of TEV protease per milligram of YjeQ was added to the pooled and dialyzed fractions containing the wild-type or YjeQ variants. Following digestion and dialysis, the reaction was loaded onto the HiTrap Metal Chelating column (GE Healthcare Life Sciences) previously equilibrated with $50 \mathrm{mM}$ Tris- $\mathrm{HCl}$ at $\mathrm{pH} 8.0,60 \mathrm{mM}$ imidazole, $0.2 \mathrm{M}$ $\mathrm{NaCl}$, and $5 \%[\mathrm{v} / \mathrm{v}]$ glycerol. The flow through containing the untagged protein was recovered and purity of fractions showing cleaved protein was monitored by $15 \%$ SDS-PAGE. Fractions with 
pure, cleaved protein were dialyzed overnight at $4^{\circ} \mathrm{C}$ against buffer containing $50 \mathrm{mM}$ Tris- $\mathrm{HCl}$ at $\mathrm{pH} 8.0$ and $5 \%$ [v/v] glycerol. For YjeQ M1, YjeQ M2, and YjeQ M3 the dialysis buffer also included $120 \mathrm{mM} \mathrm{NaCl}$. Pure proteins were concentrated using a $10 \mathrm{kDa}$-cutoff filter (Amicon). Proteins were frozen in liquid nitrogen and stored at $-80^{\circ} \mathrm{C}$.

The RbfA protein containing an amino-terminal $\mathrm{His}_{6}$-tag was overexpressed in E. coli BL21-DE3 cells transformed with the pET15b-rbfA plasmid. One liter of cells was grown in LB medium at $37^{\circ} \mathrm{C}$ to an $\mathrm{OD}_{600}$ of 0.6 and then induced with $1 \mathrm{mM}$ isopropyl $\beta$-D-1-thiogalactopyranoside (IPTG) for $3 \mathrm{~h}$ at $37^{\circ} \mathrm{C}$. Following induction, cells were harvested and lysed using the same protocol and buffers as in the case of the YjeQ protein. The first step of purification of RbfA included a HiTrap Metal Chelating column (GE Healthcare Life Sciences) that was performed in an identical manner to the YjeQ purification except that the column washes before elution were done with buffers containing 30 and $75 \mathrm{mM}$ imidazole. Fractions containing RbfA protein were collected, pooled, and dialyzed overnight at $4^{\circ} \mathrm{C}$ against buffer containing $50 \mathrm{mM}$ Tris- $\mathrm{HCl}$ at $\mathrm{pH} 8.0$ and $5 \%$ [v/v] glycerol. Dialyzed RbfA was then loaded onto a HiTrap Q HP Anion Exchange column (GE Healthcare Life Sciences) previously equilibrated with $50 \mathrm{mM}$ Tris- $\mathrm{HCl}$ at $\mathrm{pH} 8.0$ and $5 \%[\mathrm{v} / \mathrm{v}]$ glycerol. Nonspecifically bound proteins were washed with $50 \mathrm{mM} \mathrm{NaCl}$ and RbfA was eluted by increasing the $\mathrm{NaCl}$ concentration to $100 \mathrm{mM}$. Purity of the fractions was monitored by $15 \%$ SDS-PAGE. Fractions with pure RbfA were dialyzed overnight at $4^{\circ} \mathrm{C}$ against buffer containing $50 \mathrm{mM}$ Tris- $\mathrm{HCl}$ at $\mathrm{pH} 8.0$ and $5 \%[\mathrm{v} / \mathrm{v}]$ glycerol and concentrated using a $10 \mathrm{kDa}$-cutoff filter (Amicon). Purified RbfA was frozen in liquid nitrogen and stored at $-80^{\circ} \mathrm{C}$. The amino-terminal $\mathrm{His}_{6}$-tag in RbfA was not removed in order to facilitate visualization of the protein in the binding assays with the $30 \mathrm{~S}$ ribosomal subunits (see below).

\section{Purification of 305 ribosomal subunits}

Parental (BW25113) and $\Delta y j e Q$ E. coli cells were used as the source for purification of the mature and immature $30 \mathrm{~S}$ ribosomal subunits. We used centrifugation over sucrose cushions and gradients as previously described (Jomaa et al. 2011a) to purify both ribosomal particles from these cells (Supplemental Fig. S5A). In the case of the mature $30 \mathrm{~S}$ subunits, sucrose gradients loaded with ribosomal particles from parental cells were resolved under "dissociating" conditions (buffer containing $1.1 \mathrm{mM}$ magnesium acetate) that leads to the dissociation of the 70S subunits and allows for an efficient purification of mature 30 S subunits. Under "associating conditions" (buffer containing $10 \mathrm{mM}$ magnesium acetate), the parental strain yielded a characteristic ribosome profile with the majority of $30 \mathrm{~S}$ subunits assembled as mature $70 \mathrm{~S}$ particles, establishing that these cells have a normal wild-type phenotype (Supplemental Fig. S5A). Immature $30 \mathrm{~S}$ subunits were purified from $\Delta y j e Q$. In this case, sucrose gradients loaded with purified ribosomes were resolved under "associating conditions." These cells typically accumulate a large proportion of free immature 30S subunits ( 39\%) (Supplemental Fig. S3A), thus these conditions allowed us to obtain a homogeneous preparation of immature subunits without contaminating mature 30 S subunits.

The rRNA analysis of 30 S subunits from parental and $\Delta y j e Q$ E. coli cells was performed to verify that our purifications of $30 \mathrm{~S}$ subunits consisted of mature and immature $30 \mathrm{~S}$ subunits, respectively
(Supplemental Fig. S5B). For each preparation, we took $\sim 10-50$ pmol of purified ribosome subunits and used the RNeasy Mini Kit (Qiagen) to purify the rRNA following manufacturer's protocols. Subsequently, purified rRNA samples from the fractions corresponding to the $30 \mathrm{~S}, 50 \mathrm{~S}$, and $70 \mathrm{~S}$ peaks in the sucrose gradients were resolved in a $0.9 \%$ synergel- $0.7 \%$ agarose gel using previously described methods (Wachi et al. 1999). This approach allows for the separation during electrophoresis of the 23S, 17S, and 16S rRNAs during electrophoresis. The preparations of mature and immature 30 S subunits did not contain any $23 \mathrm{~S}$ rRNA indicating the absence of $50 \mathrm{~S}$ subunit contamination. The purification of $30 \mathrm{~S}$ subunits from parental cells showed the presence of $16 \mathrm{~S}$ rRNA indicating that it mainly contained mature $30 \mathrm{~S}$ subunits. Instead, the $30 \mathrm{~S}$ subunits purified from $\triangle y j e Q$ cells contained exclusively $17 \mathrm{~S}$ rRNA, which is the precursor form of the mature $16 \mathrm{~S}$ rRNA, indicating that the $30 \mathrm{~S}$ subunits in these preparations were immature. The $\Delta y j e Q$ cells also contained small amounts of $16 \mathrm{~S}$ rRNA, but it was incorporated into $30 \mathrm{~S}$ subunits that were associated to the $50 \mathrm{~S}$ subunit and appeared in the $70 \mathrm{~S}$ peak of the gradient.

\section{Circular dichroism spectroscopy}

CD spectra for each YjeQ protein were collected using a Circular Dichroism Spectrometer Model 410 (Aviv Biomedical, Inc.). Spectral scans were performed from 260 to $200 \mathrm{~nm}$, with step resolution and bandwidth of $1.0 \mathrm{~nm}$. A 1-mm-path-length quartz cuvette was used for the measurements. The spectra for each protein and each temperature $\left(4^{\circ} \mathrm{C}, 16^{\circ} \mathrm{C}, 25^{\circ} \mathrm{C}\right.$, and $\left.37^{\circ} \mathrm{C}\right)$ are an average from three consecutive scans obtained during a 15 -min incubation period. Protein solutions were prepared at a concentration of 0.5 $\mathrm{mg} / \mathrm{mL}$ in Binding Buffer 300 (10 mM Tris- $\mathrm{HCl}$ at $\mathrm{pH} 8.0,7 \mathrm{mM}$ magnesium acetate, $300 \mathrm{mM} \mathrm{NH}_{4} \mathrm{Cl}$, and $1 \mathrm{mM}$ dithiothreitol [DTT]). The machine units of millidegrees ellipticity were used to calculate the mean residue molar ellipticity in $[\theta]$ using the following equation:

$$
\begin{aligned}
{[\theta]\left(\mathrm{deg} \cdot \mathrm{cm}^{2} \bullet \mathrm{dmol}^{-1}\right) } & \\
= & \text { Ellipticity }(\mathrm{mged}) \bullet 10^{6} / \text { Pathlength }(\mathrm{mm}) \\
& \bullet[\text { Protein }](\mathrm{mM}) \bullet n
\end{aligned}
$$

( $n$ is the number of peptide bonds in the protein).

\section{Binding assays}

Reactions for filtration assays to detect binding of YjeQ and RbfA to mature and immature $30 \mathrm{~S}$ subunits were prepared by mixing 200 pmol of protein (YjeQ, YjeQ variants, and/or RbfA) with 40 pmol of $30 \mathrm{~S}$ subunit in a $100 \mu \mathrm{L}$ reaction in either Binding Buffer 60 (10 $\mathrm{mM}$ Tris- $\mathrm{HCl}$ at $\mathrm{pH} 8.0,7 \mathrm{mM}$ magnesium acetate, $60 \mathrm{mM}$ $\mathrm{NH}_{4} \mathrm{Cl}, 1 \mathrm{mM}$ DTT, and $1 \mathrm{mM}$ GMP-PNP) or Binding Buffer 300 (10 mM Tris- $\mathrm{HCl}$ at $\mathrm{pH} 8.0,7 \mathrm{mM}$ magnesium acetate, $300 \mathrm{mM}$ $\mathrm{NH}_{4} \mathrm{Cl}, 1 \mathrm{mM}$ DTT, and $1 \mathrm{mM}$ GMP-PNP). The concentration of each protein assembly factor in this reaction was fivefold that of the ribosomal particle. Nucleotide (GMP-PNP, GDP, or GTP) was added where indicated to a final concentration of $1 \mathrm{mM}$. Reactions were incubated at $16^{\circ} \mathrm{C}, 25^{\circ} \mathrm{C}$, or $37^{\circ} \mathrm{C}$ for $15 \mathrm{~min}$ followed by centrifugation in a $100 \mathrm{kDa}$ Nanosep Centrifugal Devices (PALL). In cases where YjeQ was added following a 15 min incubation of RbfA with the ribosomal particle, the binding reaction was allowed to proceed 
for another $15 \mathrm{~min}$. Prior to loading the binding reactions in the 100 kDA Nanosep Centrifugal Devices (PALL), its filter membrane was blocked by loading $500 \mu \mathrm{L}$ of $1 \%[\mathrm{w} / \mathrm{v}]$ BSA and washed twice with $500 \mu \mathrm{L}$ of RNase free water. Reactions were spun at $12,000 \mathrm{~g}$ for $10 \mathrm{~min}$ to separate $30 \mathrm{~S}$ particles and $30 \mathrm{~S}$-bound proteins that were retained by the filter from unbound proteins in flow-through (FT). The flow-through was collected and the filter was washed gently twice with $100 \mu \mathrm{L}$ of Binding Buffer 60 or 300, followed by a 5 min spin at $12,000 \mathrm{~g}$. Finally, the $30 \mathrm{~S}$ particles and $30 \mathrm{~S}$-bound proteins retained by the filter were vigorously resuspended in $100 \mu \mathrm{L}$ of Binding Buffer 60 or 300 and collected as the bound fraction (B). To resolve the flow-through and bound fractions, $30 \mu \mathrm{L}$ of sample were mixed with $6 \times$ SDS-PAGE loading buffer and loaded into a $4 \%-12 \%$ Criterion XT Bis-tris gel (Bio-Rad). Samples were run in XT MOPS buffer (Bio-Rad). Gels were stained with Coomassie blue.

In the case of the pelleting assays, reactions were prepared by mixing $250 \mathrm{pmol}$ of protein (YjeQ, YjeQ variants, and/or RbfA) with 50 pmol of $30 \mathrm{~S}$ particle in a $50 \mu \mathrm{L}$ reaction in either Binding Buffer 60 or Binding Buffer 300. The final concentration of GMP-PNP in the binding reactions containing YjeQ and YjeQ variants was $2 \mathrm{mM}$. Reactions were incubated at $16^{\circ} \mathrm{C}, 25^{\circ} \mathrm{C}$, or $37^{\circ} \mathrm{C}$ for $15 \mathrm{~min}$. In cases where RbfA was added following a $15 \mathrm{~min}$ incubation of YjeQ with the ribosomal particle, the binding reaction was allowed to proceed for another $15 \mathrm{~min}$. Following incubation, reactions were laid over a $150 \mu \mathrm{L} 1.1 \mathrm{M}$ sucrose cushion in either Binding Buffer 60 or 300 and spun for $250,000 \mathrm{~g}$ for $5 \mathrm{~h}$. The supernatant (S) containing free protein that did not pellet with the $30 \mathrm{~S}$ subunits was collected. The pellet (P) containing the $30 \mathrm{~S}$ particles and $30 \mathrm{~S}$-bound proteins was resuspended in $200 \mu \mathrm{L}$ of Binding Buffer 60 or 300 . To resolve the supernatant and pellet fractions, $30 \mu \mathrm{L}$ of sample was mixed with $6 \times$ SDSPAGE loading buffer and loaded into a $4 \%-12 \%$ Criterion XT Bistris gel (Bio-Rad). Samples were run in XT MOPS buffer (Bio-Rad). Gels were stained with Coomassie blue.

Image Lab (V5) software (Bio-rad) was used to perform a densitometry analysis on the Coomassie stained gels for relative quantification of assembly factors binding to 30 S subunits. Specifically, the lanes were automatically detected using a background subtraction with a disc size of $5 \mathrm{~mm}$. Bands were then automatically detected using high sensitivity settings (sensitivity: 5 , size scale: 7 , noise filter: 4 , shoulder: 1) followed by manual adjustment of both lanes and bands to ensure accurate measurements. The quantity tools implemented with the Image Lab software package were used to determine the relative amounts of each assembly factor in the bound portion (YjeQ or $\mathrm{RbfA}$ ) to the $\mathrm{S} 4$ protein within the same lane. Binding of wild-type YjeQ or RbfA to the mature or immature 30 S subunit was considered as 1 and all other binding interactions were quantified with respect to this value. Prior to the quantification of the bands for YjeQ, YjeQ, variants and RbfA, their intensity was normalized to account for small differences in the amount of binding reaction loaded in the gel. To this end, we used the band for r-protein S4, which should have constant intensity in all binding reactions regardless of whether mature or immature 30 S subunits were used. The r-protein S4 is not partially depleted in the immature $30 \mathrm{~S}$ subunits purified from the $\Delta y j e Q$ E. coli cells.

\section{GTPase activity assays}

The intrinsic initial rates of GTP hydrolysis of the full-length YjeQ and YjeQ variants were measured by incubating each protein $(100$
$\mathrm{nM})$ with GTP $(250 \mu \mathrm{M})$ at $25^{\circ} \mathrm{C}$ for $60 \mathrm{~min}$ and then measuring the release of free phosphate using the Malachite Green Phosphate Assay Kit (BioAssay Systems). The reactions were initiated by adding GTP to the proteins in reaction buffer containing $10 \mathrm{mM}$ Tris- $\mathrm{HCl}$ at $\mathrm{pH}$ 8.0, $7 \mathrm{mM}$ magnesium acetate, $300 \mathrm{mM} \mathrm{NH}_{4} \mathrm{Cl}$, and $1 \mathrm{mM}$ DTT. In those cases where the stimulation of the GTPase activity of YjeQ or YjeQ variants by the $30 \mathrm{~S}$ particles was measured, the sample also contained $100 \mathrm{nM}$ of $30 \mathrm{~S}$ particle before GTP was added. Volume of the reactions was $80 \mu \mathrm{L}$. Reactions were terminated by addition of $20 \mu \mathrm{L}$ of the malachite green reagent and an additional incubation of $15 \mathrm{~min}$ at $25^{\circ} \mathrm{C}$ before monitoring color formation by measuring the absorbance at $620 \mathrm{~nm}$. Values were plotted against a standard curve of free phosphate in the same reaction buffer. The amount of phosphate produced by the reaction containing only buffer and GTP was considered background and was subtracted from each reaction. To calculate the fold-increase of the initial rate, the background level of GTP hydrolysis of the 30S particle by itself was subtracted from the value obtained for the reaction containing YjeQ and the 30 S subunit. Reactions were run in a 96-well plate and readings were done with the Infinite M1000 multiplate reader (TECAN). Average and standard deviation values were derived from three replicas of each reaction. We determined that under the conditions used to measure GTPase activity, the amount of free phosphate produced in the reactions was within the linear range of the assay.

\section{Culture growth conditions}

The growth rate of the null yjeQ and parental E. coli (BW25113) strains was determined by growing the cells at $25^{\circ} \mathrm{C}$ for $47 \mathrm{~h}$ with shaking. Culture density was monitored by measuring the optical density at $600 \mathrm{~nm}\left(\mathrm{OD}_{600}\right)$ in a Sunrise 96-well plate reader (TECAN) and plotted using Magellan (TECAN). Doubling times were calculated according to the formula DT $=(t 2-t 1) \times[\log 2 /$ $\left.\left(\log \mathrm{OD}_{600} @ t 2 / \log \mathrm{OD}_{600} @ t 1\right)\right]$ and expressed in hours. Growth rates were calculated as $k=\ln 2 / \mathrm{DT}$ and expressed in $\mathrm{h}^{-1}$.

The growth curves were produced by inoculating $200 \mu \mathrm{L}$ of $\mathrm{LB}$ media from overnight cultures at 1:100 dilutions. To reintroduce the YjeQ or YjeQ M3 variant, we used the high-copy plasmid pCA24N. The pCA24N-empty and pCA24N-yjeQ plasmids were purified from the ASKA collection, which contains a complete set of open reading frame clones of $E$. coli (Kitagawa et al. 2005). The pCA24N-yjeQ plasmid expresses the amino-terminal histidinetagged YjeQ under the control of the IPTG-inducible promoter $\mathrm{P}_{\text {T5-lac. }}$ The pCA24N-yjeQM3 plasmid was constructed from the pCA24N-yjeQ plasmid using QuikChange II XL Site-Directed Mutagenesis Kit (Agilent Technologies) to introduce a stop codon in the position of Lys 320. We used standard protocols (Sambrook et al. 1989) to transform these plasmids into the $\Delta y j e Q$ cells before proceeding to obtain the growth curves as described above. In the cultures where we wanted to express YjeQ or the YjeQ M3 variant (or pCA24N-empty plasmid) the LB media contained either $1 \mu \mathrm{M}$ or $100 \mu \mathrm{M}$ IPTG as specified.

To obtain the ribosome profiles and analyze the rRNA content of these cells, LB cultures $(1 \mathrm{~L})$ were grown at $25^{\circ} \mathrm{C}$ to an $\mathrm{OD}_{600}$ of 0.2 . In the case of the strains containing the pCA24N-empty plasmid or that encoding for YjeQ or YjeQ M3 variant, we added IPTG to a concentration of $1 \mu \mathrm{M}$. Following growth, $10 \mathrm{~mL}$ of culture were pelleted by centrifugation at $1400 \mathrm{~g}$ for $20 \mathrm{~min}$ and processed to 
purify the rRNA. Total rRNA was analyzed by extracting rRNA from the cell pellet with the RNeasy Mini Kit (Qiagen). The concentration of purified rRNA was measured by absorbance at $A_{260}$, where $1 \mathrm{ab}-$ sorbance unit was equivalent to $40 \mu \mathrm{g} / \mathrm{mL}$ of RNA. Approximately $0.8 \mu \mathrm{g}$ of purified rRNA was loaded on a $0.9 \%$ synergel $-0.7 \%$ agarose gel, using methods described previously to separate $23 \mathrm{~S}, 17 \mathrm{~S}$, and 16S rRNA (Wachi et al. 1999).

The remainder of the cultures were harvested by spinning the cells at $8500 \mathrm{~g}$ for $15 \mathrm{~min}$ to obtain ribosome profiles. Pellets were washed and resuspended with $20 \mathrm{~mL}$ of Buffer A (10 mM Tris- $\mathrm{HCl}$ at $\mathrm{pH}$ 7.5, $10 \mathrm{mM} \mathrm{MgCl}_{2}$, and $60 \mathrm{mM} \mathrm{KCl}$ ), divided into three conical tubes and then centrifuged at $1400 \mathrm{~g}$ for $15 \mathrm{~min}$. Each pellet was resuspended in $6 \mathrm{~mL}$ of Lysis buffer $(10 \mathrm{mM}$ Tris- $\mathrm{HCl}$ at $\mathrm{pH} 7.5$, $10 \mathrm{mM} \mathrm{MgCl}_{2}$, and $60 \mathrm{mM} \mathrm{KCl}, 0.5 \%$ [v/v] Tween 20, $1 \mathrm{mM}$ DTT, 1 tablet $/ 10 \mathrm{~mL}$ complete mini Protease Inhibitor Cocktail [Roche]), and $20 \mu \mathrm{L}$ of RNase Free DNAse (Invitrogren). The cell suspension was lysed by passing it through the French press three consecutive times at $20,000 \mathrm{lb} / \mathrm{in}^{2}$ and clarified by centrifuging at $19,000 \mathrm{~g}$ for $10 \mathrm{~min}$. Ribosomes were pelleted by centrifuging the clarified lysate at $125,000 \mathrm{~g}$ for $1 \mathrm{~h} 52 \mathrm{~min}$. The ribosomal pellet was rinsed with $1 \mathrm{~mL}$ of Buffer B (20 mM Tris- $\mathrm{HCl}$ at $\mathrm{pH} 7.5,6$ $\mathrm{mM} \mathrm{MgCl}, 30 \mathrm{mM} \mathrm{NH} \mathrm{Ml}_{4} \mathrm{Cl}$, and $1 \mathrm{mM} \mathrm{DTT}$ ) and resuspended in $3 \mathrm{~mL}$ of this same buffer for $30 \mathrm{~min}$ on ice. An equal amount of Buffer C (20 mM Tris- $\mathrm{HCl}$ at $\mathrm{pH} 7.5,6 \mathrm{mM} \mathrm{MgCl}_{2}, 800 \mathrm{mM}$ $\mathrm{NH}_{4} \mathrm{Cl}$, and $1 \mathrm{mM}$ DTT) was added and further incubated on ice for $1 \mathrm{~h}$. The mixture was clarified by centrifuging at $19,000 \mathrm{~g}$ for $10 \mathrm{~min}$ and subsequently ribosomes were pelleted by centrifuging at $125,000 \mathrm{~g}$ for $1 \mathrm{~h} 52 \mathrm{~min}$. The ribosomal pellet was rinsed with $700 \mu \mathrm{L}$ of Buffer D (20 mM Tris- $\mathrm{HCl}$ at $\mathrm{pH} 7.5,10 \mathrm{mM} \mathrm{MgCl}_{2}$, $30 \mathrm{mM} \mathrm{NH}_{4} \mathrm{Cl}$, and $1 \mathrm{mM} \mathrm{DTT}$ ) and resuspended in $700 \mu \mathrm{L}$ of the same buffer for $1 \mathrm{~h}$. The mixture was clarified by centrifuging at $19,000 \mathrm{~g}$ for $10 \mathrm{~min}$ and $10 \mathrm{~A}_{260}$ units were laid on top of $10 \mathrm{~mL}$ $10 \%-30 \%$ sucrose gradients made with Buffer E (20 mM Tris$\mathrm{HCl}$ at $\mathrm{pH} 7.5,10 \mathrm{mM} \mathrm{MgCl}_{2}, 50 \mathrm{mM} \mathrm{NH}_{4} \mathrm{Cl}$, and $1 \mathrm{mM} \mathrm{DTT}$ ). Gradients were centrifuged at $43,000 \mathrm{~g}$ for $16 \mathrm{~h}$ using a Beckman SW41 Ti swinging-bucket rotor. Gradients were then fractioned using a Brandel fractionator apparatus and an AKTAprime purification system (GE Healthcare). The elution peaks of the ribosomal subunits were monitored by absorbance at $A_{260}$.

\section{SUPPLEMENTAL MATERIAL}

Supplemental material is available for this article.

\section{ACKNOWLEDGMENTS}

We are grateful to Vivian Leong for technical assistance. This work was supported by a grant from the National Science and Engineering Research Council of Canada (RGPIN288327-12) to J.O. The funders had no role in study design, data collection and analysis, decision to publish, or preparation of the manuscript.

Received November 28, 2014; accepted March 22, 2015.

\section{REFERENCES}

Anand B, Verma SK, Prakash B. 2006. Structural stabilization of GTPbinding domains in circularly permuted GTPases: implications for RNA binding. Nucleic Acids Res 34: 2196-2205.
Baba T, Ara T, Hasegawa M, Takai Y, Okumura Y, Baba M, Datsenko KA, Tomita M, Wanner BL, Mori H. 2006. Construction of Escherichia coli K-12 in-frame, single-gene knockout mutants: the Keio collection. Mol Syst Biol 2: 2006.0008.

Ban N, Nissen P, Hansen J, Moore PB, Steitz TA. 2000. The complete atomic structure of the large ribosomal subunit at $2.4 \AA$ resolution. Science 289: 905-920.

Boehringer D, O'Farrell HC, Rife JP, Ban N. 2012. Structural insights into methyltransferase KsgA function in 30S ribosomal subunit biogenesis. J Biol Chem 287: 10453-10459.

Bylund GO, Wipemo LC, Lundberg LA, Wikstrom PM. 1998. RimM and RbfA are essential for efficient processing of $16 \mathrm{~S}$ rRNA in Escherichia coli. J Bacteriol 180: 73-82.

Bylund GO, Lovgren JM, Wikstrom PM. 2001. Characterization of mutations in the metY-nusA-infB operon that suppress the slow growth of a $\Delta$ rimM mutant. J Bacteriol 183: 6095-6106.

Campbell TL, Brown ED. 2008. Genetic interaction screens with ordered overexpression and deletion clone sets implicate the Escherichia coli GTPase YjeQ in late ribosome biogenesis. J Bacteriol 190: $2537-2545$.

Campbell TL, Henderson J, Heinrichs DE, Brown ED. 2006. The yjeQ gene is required for virulence of Staphylococcus aureus. Infect Immun 74: 4918-4921.

Clatterbuck Soper SF, Dator RP, Limbach PA, Woodson SA. 2013. In vivo $\mathrm{X}$-ray footprinting of pre-30S ribosomes reveals chaperone-dependent remodeling of late assembly intermediates. Mol Cell 52: 506-516.

Daigle DM, Brown ED. 2004. Studies of the interaction of Escherichia coli YjeQ with the ribosome in vitro. J Bacteriol 186: 1381-1387.

Daigle DM, Rossi L, Berghuis AM, Aravind L, Koonin EV, Brown ED. 2002. YjeQ, an essential, conserved, uncharacterized protein from Escherichia coli, is an unusual GTPase with circularly permuted G-motifs and marked burst kinetics. Biochemistry 41: 11109-11117.

Datta PP, Wilson DN, Kawazoe M, Swami NK, Kaminishi T, Sharma MR, Booth TM, Takemoto C, Fucini P, Yokoyama S, et al. 2007. Structural aspects of RbfA action during small ribosomal subunit assembly. Mol Cell 28: 434-445.

Goto S, Kato S, Kimura T, Muto A, Himeno H. 2011. RsgA releases RbfA from $30 \mathrm{~S}$ ribosome during a late stage of ribosome biosynthesis. EMBO J 30: 104-114.

Guo Q, Yuan Y, Xu Y, Feng B, Liu L, Chen K, Sun M, Yang Z, Lei J, Gao N. 2011. Structural basis for the function of a small GTPase RsgA on the $30 \mathrm{~S}$ ribosomal subunit maturation revealed by cryoelectron microscopy. Proc Natl Acad Sci 108: 13100-13105.

Guo Q, Goto S, Chen Y, Feng B, Xu Y, Muto A, Himeno H, Deng H, Lei J, Gao N. 2013. Dissecting the in vivo assembly of the 30S ribosomal subunit reveals the role of RimM and general features of the assembly process. Nucleic Acids Res 41: 2609-2620.

Hall BE, Bar-Sagi D, Nassar N. 2002. The structural basis for the transition from Ras-GTP to Ras-GDP. Proc Natl Acad Sci 99: 1213812142.

Harms J, Schluenzen F, Zarivach R, Bashan A, Gat S, Agmon I, Bartels H, Franceschi F, Yonath A. 2001. High resolution structure of the large ribosomal subunit from a mesophilic eubacterium. Cell 107: 679-688.

Himeno H, Hanawa-Suetsugu K, Kimura T, Takagi K, Sugiyama W, Shirata S, Mikami T, Odagiri F, Osanai Y, Watanabe D, et al. 2004. A novel GTPase activated by the small subunit of ribosome. Nucleic Acids Res 32: 5303-5309.

Inoue K, Alsina J, Chen J, Inouye M. 2003. Suppression of defective ribosome assembly in a rbfA deletion mutant by overexpression of Era, an essential GTPase in Escherichia coli. Mol Microbiol 48: $1005-1016$

Inoue K, Chen J, Tan Q, Inouye M. 2006. Era and RbfA have overlapping function in ribosome biogenesis in Escherichia coli. J Mol Microbiol Biotechnol 11: 41-52.

Jomaa A, Stewart G, Martin-Benito J, Zielke R, Campbell TL, Maddock JR, Brown ED, Ortega J. 2011a. Understanding ribosome 
assembly: the structure of in vivo assembled immature $30 \mathrm{~S}$ subunits revealed by cryo-electron microscopy. RNA 17: 697-709.

Jomaa A, Stewart G, Mears JA, Kireeva I, Brown ED, Ortega J. 2011b. Cryo-electron microscopy structure of the $30 \mathrm{~S}$ subunit in complex with the YjeQ biogenesis factor. RNA 17: 2026-2038.

Jomaa A, Jain N, Davis JH, Williamson JR, Britton RA, Ortega J. 2014 Functional domains of the $50 \mathrm{~S}$ subunit mature late in the assembly process. Nucleic Acids Res 42: 3419-3435.

Kitagawa M, Ara T, Arifuzzaman M, Ioka-Nakamichi T, Inamoto E, Toyonaga H, Mori H. 2005. Complete set of ORF clones of Escherichia coli ASKA library (a complete set of E. coli K-12 ORF archive): unique resources for biological research. DNA Res 12: 291-299.

Leong V, Kent M, Jomaa A, Ortega J. 2013. Escherichia coli rimM and $y j e Q$ null strains accumulate immature 30 S subunits of similar structure and protein complement. RNA 19: 789-802.

Levdikov VM, Blagova EV, Brannigan JA, Cladiere L, Antson AA, Isupov MN, Séror SJ, Wilkinson AJ. 2004. The crystal structure of YloQ, a circularly permuted GTPase essential for Bacillus subtilis viability. J Mol Biol 340: 767-782.

Li N, Chen Y, Guo Q, Zhang Y, Yuan Y, Ma C, Deng H, Lei J, Gao N. 2013. Cryo-EM structures of the late-stage assembly intermediates of the bacterial 50S ribosomal subunit. Nucleic Acids Res 41: 7073-7083.

Nichols CE, Johnson C, Lamb HK, Lockyer M, Charles IG, Hawkins AR, Stammers DK. 2007. Structure of the ribosomal interacting GTPase YjeQ from the enterobacterial species Salmonella typhimurium. Acta Crystallogr Sect F Struct Biol Cryst Commun 63: 922-928.

Pettersen EF, Goddard TD, Huang CC, Couch GS, Greenblatt DM, Meng EC, Ferrin TE. 2004. UCSF Chimera-a visualization system for exploratory research and analysis. J Comput Chem 25: 16051612 .
Ramakrishnan V. 2002. Ribosome structure and the mechanism of translation. Cell 108: 557-572.

Sambrook J, Fritsch EF, Maniatis T. 1989. Molecular cloning: a laboratory manual. Cold Spring Harbor Laboratory Press, Cold Spring Harbor, NY.

Shajani Z, Sykes MT, Williamson JR. 2011. Assembly of bacterial ribosomes. Annu Rev Biochem 80: 501-526.

Sharma MR, Barat C, Wilson DN, Booth TM, Kawazoe M, HoriTakemoto C, Shirouzu M, Yokoyama S, Fucini P, Agrawal RK. 2005. Interaction of Era with the $30 \mathrm{~S}$ ribosomal subunit implications for 30S subunit assembly. Mol Cell 18: 319-329.

Shin DH, Lou Y, Jancarik J, Yokota H, Kim R, Kim SH. 2004. Crystal structure of YjeQ from Thermotoga maritima contains a circularly permuted GTPase domain. Proc Natl Acad Sci 101: 13198-13203.

Wachi M, Umitsuki G, Shimizu M, Takada A, Nagai K. 1999. Escherichia coli cafA gene encodes a novel RNase, designated as RNase G, involved in processing of the $5^{\prime}$ end of $16 \mathrm{~S}$ rRNA. Biochem Biophys Res Commun 259: 483-488.

Wilson DN, Nierhaus KH. 2007. The weird and wonderful world of bacterial ribosome regulation. Crit Rev Biochem Mol Biol 42: 187-219.

Wimberly BT, Brodersen DE, Clemons WM Jr, Morgan-Warren RJ, Carter AP, Vonrhein C, Hartsch T, Ramakrishnan V. 2000. Structure of the 30S ribosomal subunit. Nature 407: 327-339.

Woodson SA. 2008. RNA folding and ribosome assembly. Curr Opin Chem Biol 12: 667-673.

Woodson SA. 2011. RNA folding pathways and the self-assembly of ribosomes. Acc Chem Res 44: 1312-1319.

Yang Z, Guo Q, Goto S, Chen Y, Li N, Yan K, Zhang Y, Muto A, Deng H, Himeno H, et al. 2014. Structural insights into the assembly of the $30 \mathrm{~S}$ ribosomal subunit in vivo: functional role of S5 and location of the 17S rRNA precursor sequence. Protein Cell 5: 394-407. 

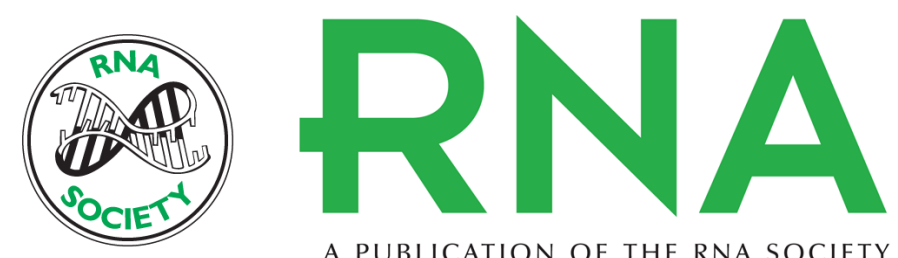

A PUBLICATION OF THE RNA SOCIETY

\section{The C-terminal helix in the YjeQ zinc-finger domain catalyzes the release of RbfA during $30 \mathrm{~S}$ ribosome subunit assembly}

Ajitha Jeganathan, Aida Razi, Brett Thurlow, et al.

RNA 2015 21: 1203-1216 originally published online April 22, 2015

Access the most recent version at doi:10.1261/rna.049171.114

\section{Supplemental http://rnajournal.cshlp.org/content/suppl/2015/04/14/rna.049171.114.DC1 \\ Material}

References This article cites 39 articles, 14 of which can be accessed free at: http://rnajournal.cshlp.org/content/21/6/1203.full.html\#ref-list-1

Open Access Freely available online through the RNA Open Access option.

Creative This article, published in RNA, is available under a Creative Commons License Commons (Attribution 4.0 International), as described at

License http://creativecommons.org/licenses/by/4.0/.

Email Alerting Receive free email alerts when new articles cite this article - sign up in the box at the Service top right corner of the article or click here.

To subscribe to $R N A$ go to:

http://rnajournal.cshlp.org/subscriptions 